\title{
Microenvironmental Determinants of Breast Cancer Metastasis: Focus on the Crucial Interplay Between Estrogen and Insulin/Insulin-Like Growth Factor Signaling
}

\section{OPEN ACCESS}

Edited by:

Marzia Di Donato,

University of Campania Luigi Vanvitelli,

Reviewed by:

Derek LeRoith,

Icahn School of Medicine at Mount

Sinai, United States

Carol Ann Lange,

University of Minnesota Twin Cities,

United States

*Correspondence:

Marcello Maggiolini

marcellomaggiolini@yahoo.it

Antonino Belfiore

antonino.belfiore@unict.it

${ }^{\dagger}$ These authors have contributed equally to this work

Specialty section:

This article was submitted to Molecular and Cellular Oncology,

a section of the journal

Frontiers in Cell and Developmental

Biology

Received: 20 September 2020

Accepted: 09 November 2020

Published: 08 December 2020

Citation:

Vella V, De Francesco EM, Lappano R, Muoio MG, Manzella L, Maggiolini M and Belfiore A (2020) Microenvironmental Determinants

of Breast Cancer Metastasis: Focus on the Crucial Interplay Between Estrogen and Insulin/Insulin-Like

Growth Factor Signaling. Front. Cell Dev. Biol. 8:608412. doi: 10.3389/fcell.2020.608412

\author{
Veronica Vella ${ }^{1 \dagger}$, Ernestina Marianna De Francesco ${ }^{1 \dagger}$, Rosamaria Lappano ${ }^{2 \dagger}$, \\ Maria Grazia Muoio ${ }^{1,2}$, Livia Manzella ${ }^{3,4}$, Marcello Maggiolini2* and Antonino Belfiore ${ }^{1 *}$ \\ 'Endocrinology, Department of Clinical and Experimental Medicine, University of Catania, Garibaldi-Nesima Hospital, \\ Catania, Italy, ${ }^{2}$ Department of Pharmacy, Health and Nutritional Sciences, University of Calabria, Rende, Italy, ${ }^{3}$ Center \\ of Experimental Oncology and Hematology, Azienda Ospedaliera Universitaria (A.O.U.) Policlinico Vittorio Emanuele, Catania, \\ Italy, ${ }^{4}$ Department of Clinical and Experimental Medicine, University of Catania, Catania, Italy
}

The development and progression of the great majority of breast cancers $(\mathrm{BCs})$ are mainly dependent on the biological action elicited by estrogens through the classical estrogen receptor (ER), as well as the alternate receptor named G-proteincoupled estrogen receptor (GPER). In addition to estrogens, other hormones and growth factors, including the insulin and insulin-like growth factor system (IIGFs), play a role in BC. IIGFs cooperates with estrogen signaling to generate a multilevel cross-communication that ultimately facilitates the transition toward aggressive and lifethreatening BC phenotypes. In this regard, the majority of $\mathrm{BC}$ deaths are correlated with the formation of metastatic lesions at distant sites. A thorough scrutiny of the biological and biochemical events orchestrating metastasis formation and dissemination has shown that virtually all cell types within the tumor microenvironment work closely with BC cells to seed cancerous units at distant sites. By establishing an intricate scheme of paracrine interactions that lead to the expression of genes involved in metastasis initiation, progression, and virulence, the cross-talk between BC cells and the surrounding microenvironmental components does dictate tumor fate and patients' prognosis. Following (i) a description of the main microenvironmental events prompting BC metastases and (ii) a concise overview of estrogen and the IIGFs signaling and their major regulatory functions in $\mathrm{BC}$, here we provide a comprehensive analysis of the most recent findings on the role of these transduction pathways toward metastatic dissemination. In particular, we focused our attention on the main microenvironmental targets of the estrogen-IIGFs interplay, and we recapitulated relevant molecular nodes that orientate shared biological responses fostering the metastatic program. On the basis of available studies, we propose that a functional cross-talk between estrogens and IIGFs, by affecting the BC microenvironment, may contribute to the metastatic process and may be regarded as a novel target for combination therapies aimed at preventing the metastatic evolution.

Keywords: breast cancer, metastasis, estrogen receptor, GPER, insulin/IGF signaling, tumor microenvionment, targeted therapies 


\section{INTRODUCTION}

Breast cancer (BC) is the most common tumor in women and the second cause of cancer-related death worldwide (DeSantis et al., 2019). The metastatic evolution, which occurs in nearly $50 \%$ of BC patients, seriously thwarts the clinical management of the disease, thereby representing one of the main determinants of BC mortality (DeSantis et al., 2019). Consequently, enormous research effort is currently focused on a better understanding of the multiple molecular and biological factors facilitating the formation and spread of metastases. In this vein, gene signatures specifically discriminating between metastatic and non-metastatic tumors have been identified (Ramaswamy et al., 2003), allowing to postulate that the metastatic propensity is established in the early stages of oncogenesis by three major classes of genes: (i) genes controlling the metastasis initiation, (ii) genes controlling the metastasis progression, and (iii) genes controlling the metastasis virulence (Nguyen and Massagué, 2007). In addition, it is now recognized that most of these genes activated in cancer cells coopt microenvironmental signals to prompt the metastatic process in diverse tumor types, including $\mathrm{BC}$. Indeed, the acquisition of metastatic features requires a complex and coordinated interaction between the epithelial BC cells and the surrounding tumor microenvironment, which is characterized by cellular (stromal fibroblasts, adipocytes, cancer stem cells (CSCs), and endothelial and immune cells) and non-cellular [growth factors and hormones, extracellular matrix (ECM) molecules, cytokines, and low oxygen] components that actively cooperate toward the metastatic landscape (Hanahan and Coussens, 2012). In this context, it should be mentioned that certain metabolic conditions associated with dysfunctional hormonal status, such as obesity and type 2 diabetes, may contribute to metastasis formation in BC, as suggested by epidemiological evidence indicating an elevated risk of metastasis in diabetic and obese patients (Park et al., 2017; Harding et al., 2020). Likewise, worse prognostic parameters have been detected in this subpopulation of BC patients (Schrauder et al., 2011; Zhao and Ren, 2016). Notwithstanding the aforementioned epidemiological correlations, the molecular mechanisms underlying the high risk and poor outcome of obese and diabetic BC patients are complex and multifactorial. First, adipose tissue does contribute to the local production of estrogens, which exert a potent stimulatory action on cancer cells binding to the classical estrogen receptor (ER), as well as the alternate G-protein-coupled estrogen receptor (GPER) (Barton et al., 2018). In addition, obesity facilitates the establishment of hyperinsulinemia and insulin resistance, thereby determining an unopposed activation of the insulin receptor (IR) and the insulin-like growth factor receptor (IGF-1R) (Lewitt et al., 2014), which are part of the complex insulin/IGF system (IIGFs). IIGFs comprises insulin, IGF-1, IGF-2 (IGFs) and cognate receptors (IR, IGF-1R, IR/IGF-1R hybrids, and IGF-2R also known as the mannose 6-phosphate receptor) and six IGFbinding proteins (IGF-BP1-6) (Frasca et al., 2008). IIGFs is deeply deregulated in diverse type of tumors, including BC, and it has been implicated in the acquisition of the metastatic potential (Frasca et al., 2008; Vigneri et al., 2015; Manzella et al.,
2019). Noteworthy, both IIGFs and estrogen signaling promote paracrine responses that endow cross-communications within the diverse components of the breast tumor microenvironment toward metastatic progression. In addition, complex networks of molecular and functional connections between these signaling systems appear to elicit a relevant role in BC metastasis. Herein, we first provide a comprehensive analysis of the most significant components of the tumor microenvironment involved in the activation of metastatic programs in BC. Next, we emphasize the molecular and functional interplay between estrogen and IIGFs signaling in activating BC microenvironment toward the acquisition of a metastatic phenotype. Finally, we propose that targeting the dysfunctional interactions between the IIGFs and the estrogen pathways may represent a promising tool in comprehensive therapeutic approaches aimed at halting the aberrant microenvironment in the metastatic BC.

\section{MICROENVIRONMENTAL PLAYERS INVOLVED IN BC METASTASIS}

Despite being considered a biologically inefficient process, as only few of the cancer cells released in the bloodstream actually develop secondary tumors, metastases remain one of the most intriguing and investigated aspects of tumor biology for their huge impact on prognosis. Likewise, the vast majority of BC-related deaths are due to metastases, which target mainly the bone (50-75\%), lung (17\%), brain (16\%), and liver (6\%) (Wei and Siegal, 2017). BC cells can escape the primary tumor, sneaking into the circulatory system and reaching distant sites where the neoplastic cells can either form a novel tumor mass straight after or enter a dormant state that can end up in disease relapse. Accordingly, the formation of overt secondary tumors can occur even many years after the diagnosis of the primary disease, as tumor cells disseminated at secondary sites may remain indolent for protracted period of times, until systemic and local factors cooperate toward the waken-up of dormant tumors. The macroenvironmental and microenvironmental mechanisms regulating cancer cell detachment from primary site and colonization at secondary target tissues, as well as entry and exit from dormancy, are likely to determine the fate of incipient tumors and therefore the prognosis of patients. In this paragraph, we provide an overview of the main microenvironmental players involved in $\mathrm{BC}$ metastasis, in order to provide a propaedeutic outline for depicting the cooperation of estrogen and IIGF signaling in triggering metastasis dissemination. For descriptive purposes, the aforementioned players will be categorized according to their role in (i) metastasis initiation, (ii) metastasis progression, and (iii) metastasis virulence.

\section{Metastasis Initiation}

Metastasis initiation refers to the complex coordination of the biological processes determining tumor outgrowth and angiogenesis, thereby prompting cancer cell entry into the bloodstream. A better understanding of the microenvironmental mechanisms regulating the expression of genes involved in 
metastasis initiation in $\mathrm{BC}$ is pivotal to deciphering the role of estrogenic and IIGFs signaling in the early stages of metastatic switch. In $\mathrm{BC}$, the initiation of metastasis appears to be abundantly regulated by microenvironmental events that promote epithelial-to-mesenchymal transition (EMT), the formation of CSCs, the activation of neoangiogenesis, and the instigation of local invasion.

EMT occurs when epithelial cells are reprogrammed to acquire mesenchymal traits, endowing BC cells with increased detachment propensity, enhanced motility, and invasive capability, as well as augmented intravasation capacity (Polyak and Weinberg, 2009). Clearly, EMT entails a profound change in cytoskeleton organization and a marked inclination to loosen cell-cell junctions that disrupt the contiguity of the epithelium and facilitate the breaching of basement membrane. A number of environmental clues originating from diverse cell types within the tumor milieu may activate EMT programs in BC. The most important regulatory factors in EMT are hormones, growth factors [IGFs, hepatocyte growth factor (HGF), epidermal growth factor [EGF], platelet-derived growth factor [PDGF], transforming growth factor $\beta$ (TGF- $\beta$ )], and cytokines/chemokines (Polyak and Weinberg, 2009). In addition, developmental signaling pathways (Wnt, Notch, and Sonic hedgehog), ECM components (collagen, hyaluronic acid, integrins), and local hypoxia may contribute to the modulation of EMT (Polyak and Weinberg, 2009).

These stimuli converge on several EMT-inducing transcription factors such as Snail, Slug, Zeb1, Zeb2, Twist, FoxC2, and Goosecoid (Polyak and Weinberg, 2009), with the ultimate aim to repress $\mathrm{CDH} 1$ (E-cadherin) transcription, thereby reducing epithelial differentiation and promoting a mesenchymal phenotype. It is worth recalling the enormous heterogeneity of microenvironmental cell types involved in the production of breast EMT-inducing molecules. For instance, stromal cancer-associated fibroblasts (CAFs) expressing Snail1 are associated with a high degree of desmoplastic areas with anisotropic fibers, together with lymph node involvement and worse prognosis in infiltrating BC (Stanisavljevic et al., 2015). Likewise, Snail-1 depletion in CAFs hampered their paracrine activity toward metastatic invasion, as supported by animal models of BC co-xenografted with BC cells and Snaill-deficient CAFs (Alba-Castellón et al., 2016). Together with fibrous stroma, also adipose stroma is involved in BC EMT toward the acquisition of metastatic potential. In this regard, it has been shown that when cocultured with adipocytes, BC cells may acquire EMT-like phenotypic changes associated with Twist-1 activation and higher migratory and invasive capability (Lee et al., 2015). Extending these findings, transcription factors classically associated with EMT programs have been shown to impact also other aspects of BC progression, including inflammation and antitumor immunity. This is the case for the transcription factor ZEB (zinc finger E-box-binding protein 1), whose global transcriptional regulation profile has been investigated by chromatin immunoprecipitation and RNA sequencing, followed by gene set enrichment analysis of ZEB1bound genes in BC cells. Using this approach, the authors identified a ZEB1-regulated inflammatory phenotype associated with the production of cytokines classically related with poor prognosis and metastasis, including interleukin 6 (IL-6) and IL-8 (Katsura et al., 2017). Of note, in EMT-activated BC cells, the immune checkpoint ligand PD-L1 was shown to be up-regulated in a Zeb-1-dependent manner (Noman et al., 2017), reinforcing the evidence that EMT-associated gene signatures correlate with increased inflammatory immune cell infiltration toward BC aggressiveness (Mak et al., 2016). It should be mentioned that EMT also serves as a reprogramming tool through which cancer cells acquire stemness features correlated with enhanced metastatic capability (Mani et al., 2008). According to the CSC hypothesis, a rare subpopulation of stem-like cells with tumorigenic, self-renewal and differentiation properties may generate all cell types within the tumor bulk (De Francesco et al., 2018b). Furthermore, metastatic proficiency is strictly linked to the abundance of cancer cells with stem features (CharafeJauffret et al., 2009). In cells undergoing EMT, mammosphere formation, used as readout for CSCs activity, is 10-fold more efficient, thereby corroborating the idea that the EMT process may serve as a source of CSCs (Mani et al., 2008). In this context, the adaptive response gene ATF3 has been proposed to integrate stromal signals coming from the tumor microenvironment with the acquisition of combined EMT/CSC features. More specifically ATF3, which is regulated by a number of extracellular signals including TGF- $\beta$, tumor necrosis factor $\alpha$ (TNF- $\alpha$ ), and IL-1 $\beta$, may promote morphological and molecular changes consistent with the activation of EMT, the increase of the CD24low-CD44high cells, the formation of mammospheres, the activation of motility programs, and breast tumorigenesis in vivo (Yin et al., 2010).

Transendothelial migration (TEM) precedes the dissemination of cancer cells in the circulation, thereby permitting intravasation. As a pivotal step in metastasis initiation, TEM entails a number of microenvironmental cellular and noncellular actors. Indeed, endothelial cells, vessel-associated macrophages (VAMs) and tumor-associated macrophages (TAMs) play a key role in BC cell intravasation. For instance, VAMs secrete chemoattractant molecules to recruit cancer cells at the vessel interface, whereas BC cells themselves secrete colonystimulating factor to attract macrophages in an auto-amplifying paracrine loop (Goswami et al., 2005). Moreover, macrophagesderived TNF- $\alpha$ induces the retraction of endothelial cells and their apoptosis, thus rendering vessels more loose and permeable for cancer cells invasion (Zervantonakis et al., 2012). Interesting evidences indicate that diverse signals from stromal CAFs led by TGF- $\beta$, PDGF, CXCL12/CXCR4, vascular endothelial growth factor (VEGF), and matrix metalloproteinases (MMPs) can directly drive the process of intravasation through multiple mechanisms as ECM remodeling, enhanced vessel permeability, and aberrant angiogenesis (Guo and Deng, 2018).

\section{Metastasis Progression}

The reciprocal interaction between estrogen and IIGFs signaling in BC microenvironment facilitates metastasis progression, which refers to the multiple events occurring both in the primary tumors and at metastatic sites, immediately after intravasated cancer cells enter the circulation and reach target organs. Having 
gained access to lymphatic vessels or capillaries, circulating $\mathrm{BC}$ cells disperse in the bloodstream in various directions before their extravasation at secondary site, an event that seems to be organspecific and facilitated by numerous players like components of the TME [mesenchymal stromal cells (MSCs), CAFs, TAMs], circulating cancer cells, and extravasation factors. By using a murine $\mathrm{BC}$ model of lung metastasis, $\mathrm{Yu}$ and collaborators found that MSCs maintain an inhibitory tone on lung metastasis formation through the release of the inflammatory chemokine CXCL12 and the up-regulation of the cognate receptor CXCR7 in BC cells (Yu et al., 2017). However, this effect is reversed in the presence of TGF- $\beta$, thus indicating that the prometastatic effect of MSCs depends on the simultaneous activation of inflammatory pathways like TGF- $\beta$, which is known to be activated in CAFs (Yu et al., 2017). The rapid outgrowth and expansion of the neoplastic mass generates intratumor hypoxia, which activates compensatory biological responses mediated by the transcription factors HIF (hypoxia-inducible factors) 1 and 2 (Semenza, 2012). HIF-mediated gene transcription occurs at the primary tumor, at the premetastatic niche, and ideally in all the cellular components of the TME, with the ending result of boosting the formation of metastasis (Semenza, 2012). In BC, HIF triggers the production of angiogenic factors such as VEGF to support intravasation and extravasation (Semenza, 2012). Loss of HIF-1 in triple-negative BCs (TNBCs) was associated with decreased lung metastasis through the inhibition of L1 cell adhesion molecule, which mediates $\mathrm{BC}$ cells' physical interactions with endothelial cells at the pulmonary district (Zhang et al., 2012). Of note, HIF mediates the activation of signaling systems required for $\mathrm{BC}$ invasion like the HGF/MET pathway and the RhoA/Rock signaling (Semenza, 2012). Ideally contributing to all the steps necessary for metastasis formation and dissemination, gene transcription programs dependent on HIF activation pave the way for extravasation and invasion also by triggering deep transformations of ECM. These responses require the up-regulation of lysyl oxidase enzymes (LOX, LOXL2, and LOXL4), which are produced by hypoxic $\mathrm{BC}$ cells released in the bloodstream and accumulated at premetastatic niche, where they enable the remodeling of collagen and other ECM molecules toward the intravasation of circulating BC cells (Schito and Semenza, 2016). Interestingly, certain ECM molecules such as hyaluronan not only enable tumor stroma with mechanical properties facilitating BC cell motility, but also provide CAFs with enhanced migratory capability leading to the metastasis progression (McCarthy et al., 2018). Indeed, CAFs can be found at the primary and the metastatic stroma, as well as in the circulatory system. Circulating CAFs (cCAFs) can be detected individually or in CAFs clusters, as well as in heterotypic clusters with circulating tumor cells (CTCs). It has been suggested that cCAFs generate a suitable microenvironmental niche for metastasis seeding and growth together with the escape from immune surveillance (Duda et al., 2010). In support of this hypothesis, CAFs have been detected in premetastatic niches prior to the appearance of cancer cells. Extending these findings, Ao and collaborators detected cCAFs in almost $90 \%$ of patients with metastatic BC, whereas these cell types were detected in nearly the $20 \%$ of patients with localized disease and were absent in samples from healthy donors. These observations indicate that cCAFs may serve as a tool to track and perhaps anticipate the detection of CTCs (Ao et al., 2015). CTCs, which are found as single cells or as clusters (tumor emboli), are considered as precursors of metastatic colonies. Their biology and behavior strictly depend on the tumor of origin, as well as on microenvironmental factors. For instance, a metastasis-competent subset of clustered CTCs from BC patients oligoclonally derive from primary tumor cells and are held together by plakoglobin-mediated intercellular adhesion (Aceto et al., 2014). Interestingly, elevated expression of plakoglobin in $\mathrm{BC}$ samples correlates with worse prognostic index, including worse distant metastasis-free survival, thereby reinforcing the role of CTCs and related factors in metastasis formation (Goto et al., 2017). It has become increasingly recognized that TAMs contribute to the acquisition of malignant features in $\mathrm{BC}$, through multiple mechanisms, including the formation and dissemination of metastasis. Indeed, TAMs contribute to $\mathrm{BC}$ cell migration and invasion, boost lymphangiogenesis and angiogenesis, participate in the formation of the metastatic niche and maintain a cross-communication with $\mathrm{BC}$ cells to support disease progression (Williams et al., 2016). Chemoattractant factors released by TAMs trigger tumor cells intravasation and their travel at distant sites such as lung and bone (Williams et al., 2016). Furthermore, TAMs secrete a number of proangiogenic mediators including EGF, PDGF, MIF, TNF- $\alpha$, TGF- $\beta$, IL- 8 and IL-1 $\beta$, CCL2, and CXCL8 (Williams et al., 2016). Interestingly, intravasation of BC cells facilitated by TAMs can occur also in absence of local angiogenesis, as evidenced by multiphoton microscopy in animal models of BC (Williams et al., 2016). It is been largely demonstrated that paracrine signals between TAMs and BC cells establish positive feedback loops conducive to disease progression. In particular, EGF secreted specifically by TAMs but not by $\mathrm{BC}$ cells derived from primary tumors was shown to promote cell invasion (O'Sullivan et al., 1993) and the expression of CFS-1 in BC cells. Then, CSF-1 secreted by BC cells induced the production of EGF by TAMs (Goswami et al., 2005). The pharmacological manipulation of this paracrine cycle by inhibition of either EGFR or CSF-1R was sufficient to dampen BC cell migration and invasion (Goswami et al., 2005). On the basis of the above considerations, it is evident that the BC microenvironment at the metastatic site is profoundly different from that surrounding the primary tumor. Understanding these molecular and biological differences may represent a useful tool to manipulate the tumor microenvironment in order to control the metastatic progression.

\section{Metastasis Virulence}

A number of estrogen and IIGF-regulated genes control the so-called metastasis virulence, which refers to the events that contribute to the metastatic colonization. These multifaceted responses bestow biological advantages to the secondary rather than the primary tumor, facilitating the establishment of macrometastases once locally aggressive micrometastasis have been formed. Clearly, the mechanisms regulating these responses are particularly influenced by the organospecific tropism of metastatic BC cells; however, general dynamic mechanisms governing metastasis virulence can be described. First, BC 
cells that successfully reach secondary sites are subjected to a mesenchymal-epithelial transition, which restores the epithelial phenotype. Afterward, neoplastic cells within the metastatic niche activate paracrine signaling that allow cell survival, resistance to apoptosis, evasion from immune surveillance, and colonization. Bone represents the main site for $\mathrm{BC}$ metastasis, particularly in the luminal subtypes of BC (Wei and Siegal, 2017). Metastatic BC cells hamper bone remodeling, promote bone degradation, and activate osteomimicry processes that facilitate the formation of macrometastasis (Awolaran et al., 2016). The initial trigger is represented by factors released by $\mathrm{BC}$ cells in the bone, including osteopontin (OPN), parathyroid hormone-related peptide (PTHrP), heparanase, IL1, IL-6, and prostaglandin E2. These mediators contribute to the instigation of osteolytic processes by RANKL-RANK signaling. As a consequence of osteoclasts activation, bone is degraded through the involvement of cathepsin-K, MMP-9, and MMP13. Growth factors stored in the bone matrix (TGF- $\beta$, IGF-1) are immediately released and in turn stimulate $\mathrm{BC}$ cells to secrete additional PTHrP in a vicious cycle (Waning and Guise, 2014). As it concerns brain metastasis from BC, their ability to adapt to the specific brain microenvironment is highlighted by the evidence that novel neurovascular units constituted by metastatic cells, together with microvascular cells, astrocytes, and neurons are immediately organized in the metastatic niche, where neoplastic cells may acquire a metabolic phenotype similar to the ones of resident cells (Neman et al., 2014). Very likely, this strict multicellular cooperation guarantees a better control on the brain blood barrier, thereby facilitating the access of additional CTCs, as well as an easy entry gate for nutrients. Interestingly, brain metastatic cells can activate adjacent astrocytic and glial cells that in turn secrete a number of tumor-stimulating cytokines, including IL-6, interferon $\gamma$ (IFN$\gamma$ ), tumor necrosis factor- $\alpha$ (TNF- $\alpha$ ), TGF- $\beta$, IGF- 1 , and PDGF-1 (Wang et al., 2013), thereby supporting the role of the metastatic microenvironment in the evolvement of the secondary disease. In order to survive and colonize the hostile lung environment, $\mathrm{BC}$ metastases enact a deep remodeling of the premetastatic niche through the establishment of paracrine responses at the interface between host cells and cancer cells. For instance, BC cells exhibiting a preferential tropism for the lung fuse with lung fibroblasts and release their exosomes toward the production of proinflammatory S100 proteins that facilitate the survival of metastatic cells (Hoshino et al., 2015). Additionally, the mobilization of bone marrow-derived cells initiated by the HIF/LOX pathway in hypoxic BC cells triggers ECM remodeling in the lung and facilitates the systemic instigation of indolent cancer cells through the secretion of OPN. Interestingly, Ye et al. (2015) have unveiled the ability of an inflammatory microenvironment to impact on metastasis formation at the lung. More specifically, using a mouse model of BC, the authors found that a TGF- $\beta$-driven inflammatory signature drives the secretion of cytokines involved in the formation of the premetastatic niche such as S100A8, S100A9, Angpt2, and VEGF. Last, a metastasis-favorable microenvironment has been hypothesized for liver, where larger BC metastasis can be found compared to the lung. Along with fibroblasts and TAMs, liver-specific cellular components such as Kupffer cells, liver sinusoidal endothelial cells, and hepatic stellate cells cooperate toward the establishment of metastasis (Ma R. et al., 2015). Of note, liver metastases from $\mathrm{BC}$ cells show a peculiar metabolic profile compared to bone and lung metastases. The reduction of mitochondrial metabolism and the increased rate of conversion of pyruvate into lactate by PDK1 may suggest a specific metabolic adaptation to lack of nutrients and hypoxia. Likewise, PDK1 is recognized as one of the most important regulators of liver metastasis in BC (Dupuy et al., 2015).

\section{ESTROGEN AND IIGFS SIGNALING IN BC}

Having described the main biological events and molecular mediators orchestrating the microenvironmental responses involved in BC metastasis, in this paragraph we provide a brief but sound overview of the basic signaling mechanisms mediated by estrogen and IIGFs in BC (Figure 1). Despite the description of estrogen and IIGFs pathway in epithelial BC cells goes beyond the purpose of this review, a concise sketch of the mode of action of these transduction pathways is required to understand how estrogen and IIGFs signaling work together in landscaping BC microenvironment toward metastasis propagation.

\section{Estrogen Signaling}

Estrogenic signaling facilitates the establishment of BC metastasis by activating stimulatory responses that impact the initiation, progression, and virulence of metastatic genes. Most of these genes are transcriptionally regulated by the $\mathrm{ER} \alpha$, which is expressed in approximately $70 \%$ of breast tumors identifying estrogens as master regulators of breast malignant development (Katzenellenbogen and Frasor, 2004; Yager and Davidson, 2006; Kumar et al., 2011; Rondón-Lagos et al., 2016). Consequently, $\mathrm{ER} \alpha$ is a main target of the current endocrine approaches in ER $\alpha$-positive BCs (Howell et al., 2007). Estrogen-mediated gene transcription occurs through multiple independent and sometimes cooperating mechanisms that may lead to relevant biological responses. Unliganded $\mathrm{ER} \alpha$ is principally located in the cytoplasm; however, upon ligand exposure, it dissociates from the heat shock proteins, dimerizes, and shuttles to the nuclear compartment (Stenoien et al., 2001). Then, ER $\alpha$ acts as a transcription factor binding to the estrogen-responsive elements (EREs) located on the promoter regions of target genes (Stenoien et al., 2001). Ligand-activated ER $\alpha$ may also regulate the transcription of genes in an ERE-independent manner through the interaction with other factors (McDonnell and Norris, 2002; Björnström and Sjöberg, 2005). For instance, interacting with $\mathrm{c}$-fos and c-jun proteins at the AP-1-binding sites, $E R \alpha$ may regulate the transcription of genes as IGF1 (Umayahara et al., 1994), collagenase (Webb et al., 1995), and cyclin D1 (Sabbah et al., 1999). In addition, ER $\alpha$ may contribute to rapid responses to estrogens by interacting with scaffold proteins such as caveolin-1 or signaling molecules, namely, G proteins, Src kinase, and Shc (Migliaccio et al., 1996; Razandi et al., 1999, 2002; Wyckoff et al., 2001; Song et al., 2002; 


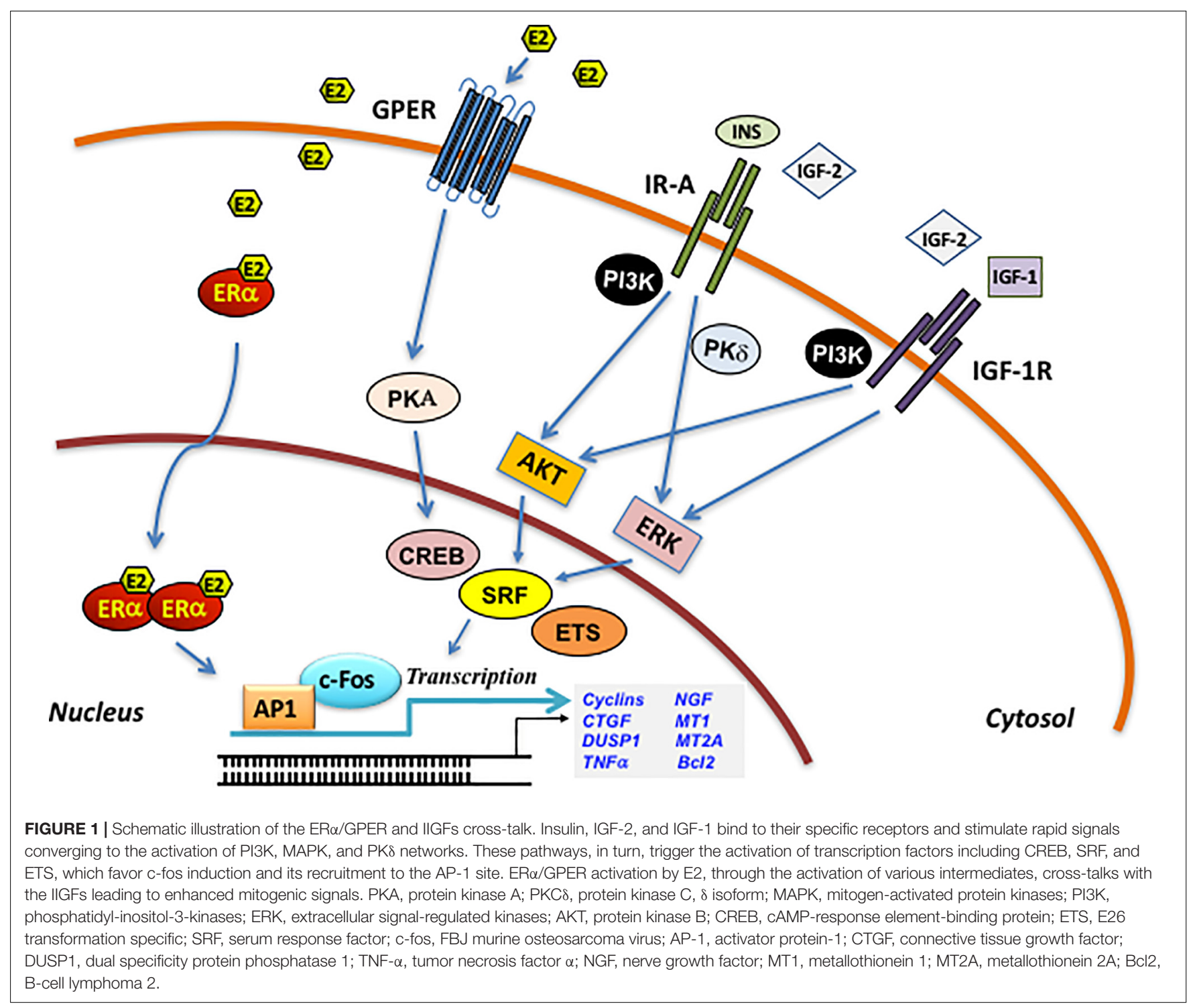

Auricchio et al., 2008; Levin and Pietras, 2008; Levin, 2009), and activate diverse extranuclear signaling cascades, such as Src, adenylyl cyclase, mitogen-activated protein kinase (MAPK), phosphatidylinositol-3-kinase (PI3K), and protein kinase C (PKC) (Migliaccio et al., 1996; Castoria et al., 2001). Likewise, upon estrogenic stimulation, $\mathrm{ER} \alpha$ engages tyrosine kinase receptors as IGF1R, the EGF receptor, and ErbB2 (HER-2/neu), triggering relevant biological effects in diverse cell contexts, including BC cells (Kahlert et al., 2000; Chung et al., 2002; Razandi et al., 2003). For instance, the ER $\alpha$-mediated activation of growth factor receptors may lead to the stimulation of the Ras/Raf/MAPK and Akt transduction cascades and then to growth responses (Kahlert et al., 2000; Chung et al., 2002; Razandi et al., 2003). Overall, the aforementioned nuclear and extranuclear-initiated pathways driven by $\mathrm{ER} \alpha$ may control a variety of biological outcomes in mammary tumor cells, ranging from cell cycle, proliferation, chromatin remodeling to survival, and motility (Ballaré et al., 2003; Levin, 2003; Qiu et al., 2003;
Castoria et al., 2004; Vicent et al., 2006; Giretti et al., 2008; Levin and Pietras, 2008; Giovannelli et al., 2012).

Along with $\mathrm{ER} \alpha$, additional mediators have been shown to convey estrogen signaling toward metastatic features. In this regard, the GPER, originally termed GPR30, is a seventransmembrane protein belonging to the G-protein-coupled receptors superfamily, which mediates the action of estrogens in numerous normal and malignant cell contexts. For instance, several studies have reported a tumor promoting effects of GPER in BC. In this regard, estrogens were shown to trigger through GPER the SRC-mediated extracellular release of heparan-bound EGF and then the activation of EGFR in ER-negative BC cells (Filardo et al., 2000). Triggering rapid kinase-associated transduction pathways (i.e., ERK1/2, PI3K/Akt, Hippo/YAP/TAZ pathway), ion channels (i.e., calcium) and second messengers (i.e., cAMP), GPER may regulate the transcription of diverse genes such as c-fos, connective tissue growth factor (CTGF), EGR1, ATF3, metalloproteases, and cyclins (Pandey et al., 2009; 
Zhou et al., 2015; Barton et al., 2018). The genomic responses to GPER activation may in turn influence BC cell growth, motility, and invasion (Lappano et al., 2014). Not only estrogens and estrogen-mimetic compounds, but also antiestrogens such as 4hydroxytamoxifen, raloxifene, and ICI182,780, may act as GPER agonists and stimulate cell survival and proliferative transduction pathways (Filardo et al., 2000; Revankar et al., 2005; Pandey et al., 2009; Prossnitz and Arterburn, 2015). A functional role for GPER in breast tumorigenesis and particularly in metastasis has also been confirmed in transgenic mouse models of mammary tumorigenesis. At later stages of tumorigenesis, GPER knockout mice showed smaller tumors respect to wild-type mice along with a reduced growth rate, histologic features typical of low aggressive tumors, and decreased lung metastases (Marjon et al., 2014). Retrospective BC analysis further supported the contribution of GPER in BC progression. In this vein, immunohistochemical studies showed that GPER levels are positively associated with tumor size, distant metastases, and recurrence in BC specimens and inversely correlated with disease-free survival in tamoxifentreated patients (Filardo et al., 2006; Liu et al., 2009; Ignatov et al., 2011). A recent bioinformatics analysis in ER-negative BCs has endorsed the aforementioned findings, proving that high GPER levels are both linked with promigratory and metastatic genes and positively correlated with a shorter disease-free interval (Talia et al., 2020). Nevertheless, some studies have reported a tumor suppressor function of GPER (Weißenborn et al., 2014; Martin et al., 2018), warranting further investigations in order to better appreciate the role of GPER in different cancer cell contexts.

\section{Insulin/IGF Signaling}

As stated above, IIGFs, an important growth regulatory pathway often overactivated in $\mathrm{BC}$, is crucially implicated in the acquisition of metastatic features.

IIGFs consists of circulating ligands (insulin, IGF-1, and IGF2), multiple receptors, and six IGF-binding proteins (Belfiore et al., 2009, 2017). The human IR exists in two isoforms (IR-A and IR-B) generated by alternative splicing of the IR gene with the exclusion (IR-A) or inclusion (IR-B) of 12 amino acids encoded by exon 11 . The IR and the IGF-1R have highly homologous structures, but different functions. Given the high degree of homology, IR and IGF-1R can heterodimerize leading to the formation of insulin/IGF-1 hybrid receptors (HRs) (Belfiore et al., 1999, 2009). The IGF-2R lacks an intracellular tyrosine kinase domain and therefore does not transduce intracellular mitogenic signals, acting mainly as a buffer for modulating IGF-2 bioactivity through IR-A and IGF-1R (El-Shewy and Luttrell, 2009). The IIGFs has a significant role not only for normal mammary gland development but also in the onset and maintenance of the malignant phenotype of BC cells. As insulin and IGFs stimulate cell growth via mitogenic, antiapoptotic and chemotactic activity, many of the steps of the normal development of the mammary gland are recapitulated during the process of metastasis (Gallagher and LeRoith, 2011). Indeed, IIGFs is implicated in tumor progression and metastasis of both ER-positive and ER-negative BC cells (Bartella et al., 2012; De Marco et al., 2015) and frequently shows features of deregulation such as (i) overexpression and activation of IGF-1R,
IR, and IR/IGF-1R hybrids in malignant cells, (ii) dysregulated expression and/or bioavailability of IGF-1 and IGF-2 in both malignant and stromal cells, and (iii) increased IR-A:IR-B ratio and establishment of IR-A/IGF2 autocrine/paracrine loops (Malaguarnera et al., 2012a). IR-A is also termed the "oncofetal" IR isoform as it exerts a pivotal role in promoting fetal growth by acting as a promiscuous receptor that binds not only insulin but also IGF-2, proinsulin, and IGF-1 (Belfiore and Malaguarnera, 2011; Malaguarnera and Belfiore, 2014; Belfiore et al., 2017). In fact, proinsulin, the insulin prohormone, which is increased in fetal life and insulin resistance conditions, is a high-affinity IR-A ligand (Malaguarnera et al., 2012b) and stimulates proliferation and migration in $\mathrm{BC}$ cells.

The increased IR-A:IR-B ratio in BC cells is likely due to multiple mechanisms leading to dysregulated expression of splicing factors involved in exon 11 skipping of the IR gene (Echeverria and Cooper, 2014) including mutations of the gene encoding for the SF3B1 splicing factor. In BC cells IR-A is considered to act as a hub for integrating signals coming from the circulation and connected with the nutritional status (insulin and proinsulin) and signals coming from the microenvironment (IGF-1 and IGF-2) (Belfiore et al., 2017). Insulin has a major orchestrating role in this context by increasing tissue IGFs' bioavailability through the dual action of enhancing IGF-1 production by the liver and concomitantly inhibiting IGF-BPs synthesis (Belfiore et al., 2017).

IR-A downstream signals show important differences when stimulated by either insulin or IGF-2, the latter being more mitogenic (Frasca et al., 1999). However, IR-A is intimately linked to the mitogenic MAPK/mammalian target of rapamycin (mTOR) cascade rather than to the PI3K/Akt metabolic cascade also in response to insulin (Frasca et al., 1999). As a consequence, $\mathrm{BC}$ cells do not share the insulin resistance of peripheral tissues of obese patients (Yee et al., 2020). Therefore, IR-A overexpression can be seen as a way BC cells exploit to overcome insulin resistance of obese patients and allow full response to the estrogen/IIGFs cross-talk (Belfiore et al., 2017). Additionally, IR-A overexpression increases the assembly of IR-A/IGF-1R hybrids that function as high-affinity binding sites for IGFs, thus amplifying signals from the microenvironment (Belfiore et al., 2009). In turn, IR-A-mediated biological responses are regulated by tumor stroma components, such as the proteoglycan decorin, which negatively modulates IGF-2 actions while leaving unaffected insulin/proinsulin effects. Thus, reduced levels of decorin associated with aggressive BCs enhance the activity of the IGF-2/IR-A loop (Morcavallo et al., 2014).

The relevance of this loop is underscored by studies showing that endocrine-resistant $\mathrm{ER}^{+} \mathrm{BCs}$ may have reduced expression of IGF-1R while expressing much higher levels of IR (Fagan et al., 2012; Yee, 2018). Similarly, data obtained in thyroid cancer indicate that loss of differentiation (Vella et al., 2002) and stemlike phenotype (Malaguarnera et al., 2011) are associated with high relative abundance of IR-A and IGF-2 secretion, while IGF-1R expression is generally reduced.

Although overexpression of IR and IGF-1R in cancer cells recognizes multiple mechanisms, which are reviewed elsewhere (Belfiore et al., 2017), a recently emerged non-mutational 
mechanism involves the collagen receptor DDR1, which is upregulated by IIGFs activation and by collagen (Vella et al., 2019a). In turn DDR1 up-regulates both IR and IGF-1R in a feedforward loop (Matà et al., 2016; Vella et al., 2017) that may enhance BC metastasis potential (see below). Interestingly, DDR1 also regulates adipose cell aromatase and estrogen output by activating a mechanotransduction pathway (Ghosh et al., 2013) representing a relevant node in the estrogen/IIGFs cross-talk.

Not surprisingly, obesity and T2DM, both characterized by insulin resistance, are associated with an increased risk of postmenopausal BC and higher rates of tumor progression and recurrence; hyperinsulinemia has been found to be a major determinant of this risk (Schrauder et al., 2011; Lewitt et al., 2014; Park et al., 2017). In this line, several studies show that women with increased circulating levels of IGF-1 and low amount of IGFBP3 may have a high risk of BC and that high levels of IGF-1 are associated with BC progression and recurrence (Belfiore et al., 2017).

To further corroborate the importance of IR-A activation in BC patients, IR phosphorylation in BC cells was a significant marker of poor patient survival (Law et al., 2008). Moreover, a high IR-A:IR-B ratio was particularly associated with the luminal $\mathrm{B}$ subtype of $\mathrm{ER}^{+} /$progesterone receptor-positive $\left(\mathrm{PR}^{+}\right) / \mathrm{HER} 2^{-}$ BCs that are clinically characterized by a higher grade, positive lymph node involvement, and poorer relapse-free survival (Huang et al., 2011).

Notably, the IIGFs is widely implicated in the process of angiogenesis, which is essential for the metastatic dissemination of tumor cells. To metastasize, cancer cells must be able to form new vessels often in hypoxic environments. VEGF-A is an important mediator of angiogenesis and is under the transcriptional control of HIF-1 and HIF-2, transcription factors induced by hypoxia and growth factors (Bielenberg and Zetter, 2015).

Consistently, IGF-1Rs are expressed in isolated hemovascular endothelial cells, newly formed blood microvessels, and in lymphatic endothelium (Bar and Boes, 1984), and IGF-1 is able to up-regulate VEGF through HIF- $1 \alpha$ in BC cells. Interestingly, GPER cooperates with HIF- $1 \alpha$ for the transcriptional activation of VEGF induced by IGF-1 in vascular endothelial cells (De Francesco et al., 2017). IR-A is also markedly overexpressed in angiogenic vasculature in human tumors and stimulates endothelial cell proliferation and in vivo angiogenesis (Belfiore et al., 2009, 2017).

Similarly, lymphangiogenesis is an important mechanism by which tumor cells are disseminated via the lymphatic system and induce lymph node metastases, which occur in the early stages of BC development and may promote further spread of BC cells at distant sites (Fidler, 2003). Both IGF-1 and IGF-2 show the ability to induce angiogenesis and lymphangiogenesis in several in vitro and in vivo model systems (Bjorndahl et al., 2005). In particular, IGF-1 induces and promotes lymphangiogenesis through the induction of VEGF-C.

Along with angiogenesis and lymphangiogenesis, IIGFs have been implicated in the mechanisms of BC cell homing, which is necessary for colonization at secondary sites. In this regard, several evidences suggest that, upon exposure to cytokines and growth factors of bone microenvironment, BC cells undergo genetic alterations that may enhance their ability to survive and colonize the bone. IGF-1 and IGF-2 are among those molecules found in bone environment together with TGF- $\beta$, PDGF, and fibroblast growth factors (FGFs) (Wissmann and Detmar, 2006). Adding to this, oncogene mutations and other molecular abnormalities leading to STAT3 activation induce IGF-2 secretion and IR-A activation toward invasive features and resistance to antitumor treatments (Lee et al., 2006). For instance, IGF-2 secreted by epithelial mammary cells expressing c-Myc oncogene activates fibroblasts that acquire the ability to remodel the ECM, thus promoting epithelial cell invasion (De Vincenzo et al., 2019). Consistently, metastatic BC CAFs have protumorigenic properties induced by increased IGF-2 expression (Gui et al., 2019).

Metabolic reprogramming is a hallmark of cancer. It is worth mentioning that we recently showed that IR-A activation by insulin and IGF-2 plays a role in BC cells metabolic reprogramming by increasing both glycolysis and oxidative phosphorylation. IGF-2-activated IR-A especially enhanced BC cell metabolic flexibility, leading to the acquisition of malignant features consistent with cellular adaptation to a challenging microenvironment characterized by high energy demand (Vella et al., 2019b).

Finally, IGF-2/IR-A loop has also been implicated in EMT (Zelenko et al., 2016) and other stem-like features (Malaguarnera et al., 2011), which play a key role in cancer development and recurrence.

Overall, these studies clearly support a pivotal role for IIGFs in aggressive traits of $\mathrm{BC}$ supportive of metastatic phenotypes.

\section{MICROENVIRONMENTAL INTERACTIONS BETWEEN ESTROGENIC SIGNALS AND IIGF CONDUCIVE TO BC METASTASIS}

As previously mentioned, mounting evidence indicates that, in BC, signals mediated by estrogens and IIGFs shape the tumor microenvironment and drive metastatic evolution. Despite these signaling systems elicit profound direct actions on BC cells themselves, understanding the role of estrogens and IIGFs and their cooperation in landscaping the tumor microenvironment toward metastatic features (Figure 2) may unveil further layers of complexity toward novel therapeutic perspectives. Estrogen/ER-mediated BC progression does involve a bidirectional cooperation between $\mathrm{BC}$ cells and components of the surrounding stroma as blood vessels, immune cells, CAFs, and other types of cells (Lappano and Maggiolini, 2018; Rothenberger et al., 2018). Stromal cells may contribute to the progression of BCs acting as a main source of soluble and non-soluble secreted factors such as hormones, growth factors, cytokines, and ECM molecules, which regulate matrix remodeling, neoangiogenesis, migration, and invasion (Lappano et al., 2020a; Tables 1, 2).

In CAFs, the estrogen-induced production of SDF- $1 \alpha$, occurring in an ER $\alpha$-independent manner, may contribute to $\mathrm{BC}$ progression through the accumulation of cancer-infiltrating 


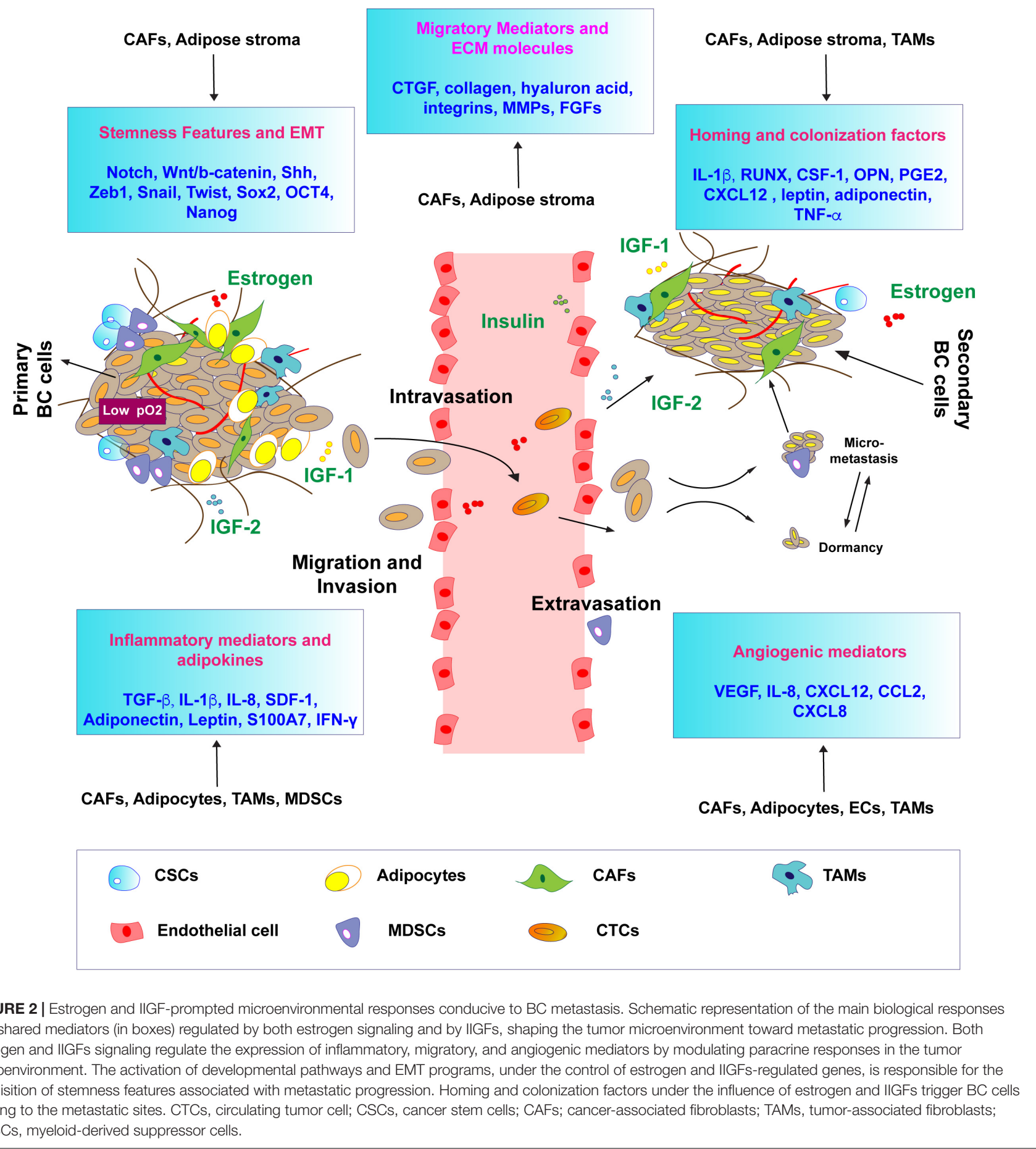

myeloid-derived suppressor cells (MDSCs) in the tumor microenvironment (Ouyang et al., 2016). In this context, it should be mentioned that growth factors released within the tumor microenvironment may modulate the function of ER $\alpha$ toward the development of breast malignant features (Bartella et al., 2012). Yet, CAFs may be targets of the stimulatory paracrine actions elicited by diverse molecules released by $\mathrm{BC}$ and/or other stromal cells (Kalluri, 2016). Among these molecules, IGF-1 and IGF-2 have been shown to be released by epithelial $\mathrm{BC}$ cells and drive the acquisition of the activated status in adjacent fibroblasts, toward increased migratory and invasive behavior (De Vincenzo et al., 2019). Conversely, IGF-1 released by CAFs triggered migratory effects in MDA-MB-231 BC cells and the formation of lung metastasis in an animal model of BC (Daubriac et al., 2018). Similarly, the paracrine release of IGF-1 by CAFs primed TNBC to metastasize the bone (Zhang et al., 2013). In parallel, the 
TABLE 1 | Schematic representation of the EMT factors modulated by estrogen and IIGF signaling in BC.

\begin{tabular}{|c|c|c|c|c|}
\hline EMT factor & Mediator & Model system & Mechanism involved & References \\
\hline Snail & IGF-1R & Human mammary epithelial cells & $\begin{array}{l}\text { Constitutively activated IGF-IR induces EMT } \\
\text { through Snail1 }\end{array}$ & Kim et al., 2007 \\
\hline NF-кB & IGF-1R & Human mammary epithelial cells & $\begin{array}{l}\text { Constitutively activated IGF-IR induces EMT } \\
\text { through Snail1 }\end{array}$ & Kim et al., 2007 \\
\hline GDF15 & IGF-1R & BC cells & $\begin{array}{l}\text { GDF-15 activates IGF-1R-FoxM1 signaling to } \\
\text { trigger EMT }\end{array}$ & Peake et al., 2017 \\
\hline TGF- $\beta$ & IGF-1R & BC cells & $\begin{array}{l}\text { IGF-1 and latent TGF- } \beta \text { promote MMPs activity } \\
\text { and EMT }\end{array}$ & $\begin{array}{l}\text { Walsh and Damjanovski, } \\
2011\end{array}$ \\
\hline Twist, Zeb, Slug & $\mathbb{R}$ & $\begin{array}{l}\text { Immunodeficient hyperinsulinemic } \\
\text { mouse models of T2DM and BC cells }\end{array}$ & Hyperinsulinemia induces IR-mediated EMT & Zelenko et al., 2016 \\
\hline Fibronectin and $\beta$-1 integrin & GPER & Tamoxifen-resistant BC cells & $\begin{array}{l}\text { GPER/EGFR/ERK signaling upregulates } \\
\beta 1 \text {-integrin expression and drives EMT }\end{array}$ & Yuan et al., 2015 \\
\hline $\mathrm{IL}-1 \beta$ & E2/GPER & BC cells and CAFs & 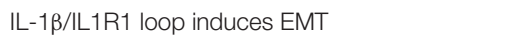 & De Marco et al., 2016 \\
\hline Notch, HIF-1 $\alpha$ & GPER & BC cells and CAFs & $\begin{array}{l}\text { A cross-talk between Notch, HIF-1 } \alpha \text {, and } \\
\text { GPER mediates EMT }\end{array}$ & De Francesco et al., 2018a \\
\hline Notch & E2/GPER & $\mathrm{BC}$ cells and CAFs & $\begin{array}{l}\text { Estrogenic GPER signaling triggers } \\
\text { Notch-dependent EMT genes }\end{array}$ & Pupo et al., 2014 \\
\hline ECM molecules & $\mathrm{ER} \alpha$ & BC cells & Loss of ER $\alpha$ triggers EMT & Bouris et al., 2015 \\
\hline
\end{tabular}

TABLE 2 | Schematic representation of the main stromal mediators involved in metastatic progression by estrogen and IIGF signaling.

\begin{tabular}{|c|c|c|c|c|c|}
\hline Mediator & Regulator & $\begin{array}{l}\text { Stromal cell of } \\
\text { origin }\end{array}$ & Target cell/tissue & Metastasis-promoting function & References \\
\hline Aromatase & Leptin, IL-6 & $\begin{array}{l}\text { CAFs, adipocytes, } \\
\text { ASCs }\end{array}$ & $\begin{array}{l}\text { BC cells and } \\
\text { microenvironment }\end{array}$ & $\begin{array}{l}\text { E2 production, cell proliferation, } \\
\text { migration, angiogenesis }\end{array}$ & $\begin{array}{l}\text { Luo et al., 2014; Kamat et al., } \\
\text { 2015; Sabol et al., } 2019\end{array}$ \\
\hline IGF-1 and IGF-2 & $\begin{array}{l}\text { Oncogenic } \\
\text { mutations }\end{array}$ & $\begin{array}{l}\text { CAFs, adipocytes, } \\
\text { ASCs }\end{array}$ & $\begin{array}{l}\mathrm{BC} \text { cells and } \\
\text { microenvironment }\end{array}$ & $\begin{array}{l}\text { Homing, colonization, angiogenesis, } \\
\text { EMT, stemness features, CAF activation }\end{array}$ & $\begin{array}{l}\text { Lee et al., 2006, 2016; De } \\
\text { Vincenzo et al., } 2019\end{array}$ \\
\hline CTGF & E2, IIGFs & CAFs & CAFs, BC cells & Migration, invasion & $\begin{array}{l}\text { Madeo and Maggiolini, 2010; } \\
\text { De Marco et al., 2013, } 2014\end{array}$ \\
\hline Notch & E2 & cscs & CSCs, BC cells & $\begin{array}{l}\text { Stemness features, migration, EMT, } \\
\text { homing }\end{array}$ & Pupo et al., 2014 \\
\hline Collagen/DDR1 & ॥GFS & CAFs & $\begin{array}{l}\mathrm{BC} \text { cells and } \\
\text { microenvironment }\end{array}$ & Migration, ECM remodeling & $\begin{array}{l}\text { Matà et al., 2016; Vella et al., } \\
2017\end{array}$ \\
\hline HIF-1 $1 \alpha$ NEGF & $\mathrm{E} 2, \mathrm{IGF}-1$ & CAFs & ECs & Angiogenesis & $\begin{array}{l}\text { De Francesco et al., 2014, } \\
2017\end{array}$ \\
\hline IL-1 $\beta$ & E2 & CAFs & $\begin{array}{l}\mathrm{BC} \text { cells and } \\
\text { microenvironment }\end{array}$ & Migration, invasion & De Marco et al., 2016 \\
\hline FGF-2 & E2 & CAFs & $\begin{array}{l}\text { BC cells and } \\
\text { microenvironment }\end{array}$ & & Santolla et al., 2019 \\
\hline OSM & Adipose stroma & Adipose stroma & CSCs & EMT, stemness features & $\begin{array}{l}\text { Lapeire et al., 2014; } \\
\text { Sanchez-Infantes et al., 2014; } \\
\text { West et al., } 2014\end{array}$ \\
\hline PDGF & IGF-1 & CAFs & $\begin{array}{l}\text { BC cells and } \\
\text { microenvironment }\end{array}$ & EMT, ECM remodeling, intravasation & $\begin{array}{l}\text { Pasanisi et al., 2008; Guo and } \\
\text { Deng, } 2018\end{array}$ \\
\hline
\end{tabular}

increased expression of IGF-2 detected in breast CAFs isolated from metastasis, compared to CAFs isolated from primary breast tumors (Gui et al., 2019), suggests that also this growth factor may play a relevant role in the paracrine actions mediated by tumor stroma and leading to the metastatic switch. Indeed, IGFs have been implicated in key stages of bone metastasis such as homing, dormancy, colonization, and expansion (Weilbaecher et al., 2011). In TNBCs, stromal CAFs were identified as the source of IGF-1 and CXCL12, which were shown to prime cells to home the CXCL12- and the IGF1-rich bone microenvironment, in a process dependent on CXCR4 and IGF-1R expression by cancer cells (Zhang et al., 2013). Both IGF-1 and IGF-2 appear to play important roles in bone colonization and expansion by metastasizing tumor cells. In a study, bone-derived IGFs stimulated metastasis of BC to bone by increasing cancer cell proliferation and survival, via AKT activation and recruitment of nuclear factor $\kappa \mathrm{B}(\mathrm{NF}-\kappa \mathrm{B})$ (Hiraga et al., 2012). Further, culture medium from cells stimulated to undergo bone resorption was found to contain high concentrations of IGF-1; notably, the anchorage-independent growth of human BC cells cultured in this medium was inhibited by the IGF-1R-neutralizing antibody (Ab) $\alpha$ IR3, but not by Abs against TGF- $\beta$, FGF-1 or FGF-2, or PDGF-BB (Hiraga et al., 2012). Additionally, growth of human $\mathrm{BC}$ cells in a human adult bone model was facilitated by active 
osteoclasts induced by RANKL, and IGFs released following bone resorption (Sangai et al., 2008). More specifically, CAF-derived IGF-2 triggered migratory effects in BC cells; this effect was elicited through the involvement of the collagen receptor DDR1 (Matà et al., 2016), which has emerged as a pivotal signaling mediator of the IIGFs. In fact, DDR1 not only serves as a receptor for collagen, but it also appears to work as an adaptor signaling molecule necessary for the transduction of IGF-mediated actions (Matà et al., 2016). Interestingly, non-canonical DDR1 signaling was shown to enable collagen action and multiorgan site metastatic reactivation of breast tumors mainly through the activation of the JAK2/STAT3 pathway and the manifestation of CSC traits (Gao et al., 2016). Therefore, collagen-DDR1 signaling may serve as one of the signaling pathways exploited for BC cells' exit from dormancy, formation of metastasis, and disease relapse. In this context, collagen-enriched ECM integrates hormonal responses toward the establishment of lung metastatic lesions (Jallow et al., 2019). In vivo, E2 was able to remodel ECM architecture in the peritumoral area and in the pulmonary premetastatic niche, thus suggesting that both collagen- and estrogen-mediated action may boost lung lesions in ER-positive tumors (Jallow et al., 2019). It should be recalled that the tumor microenvironment at metastatic sites is functionally and molecularly different from the microenvironment surrounding the primary tumor. In particular, a shift from ER-positive to ERnegative context has been detected during metastasis formation. Indeed, Forsare and collaborators interrogated primary and metastatic breast biopsies, as well as CTCs from blood samples serially collected at different timepoints, and demonstrated that the ER status evolves toward the loss of the receptor in CTCs, which reflect real-time tumor progression, as well as at distant metastasis, whereas ER is detectable at the primary tumor site (Forsare et al., 2020). Accordingly, CAFs isolated from primary and metastatic breast tumors were characterized by a differential miRNOma response to estrogens (Vivacqua et al., 2019). These observations suggest that in the microenvironment of breast tumors with aggressive phenotypes, additional mediators may be involved in the stromal response to estrogens. Among these, early studies showed that breast tumor-derived CAFs are stimulated by estrogens through a GPER-mediated nuclear function (Madeo and Maggiolini, 2010; Pupo et al., 2013; Lappano and Maggiolini, 2018). In this regard, GPER, along with the phosphorylated EGFR, was surprisingly recruited by estrogens to the promoter sequences of target genes in CAFs (Madeo and Maggiolini, 2010; Pupo et al., 2013, 2017). Hence, estrogenic GPER signaling fosters CAFs to produce a variety of secreted factors that fuel proliferation, migration, invasion, spreading, and EMT of nearby BC cells, as well as tubulogenesis in endothelial cells (De Francesco et al., 2013; Yuan et al., 2015; De Marco et al., 2016; Pisano et al., 2017; Cirillo et al., 2019; Santolla et al., 2019). In particular, the functional interaction of GPER with the EGFR, IGF1R, FGFR1, HIF-1 $\alpha$, and Notch transduction pathways may trigger the release of growth factors, such as CTGF, VEGF, and FGF2, and cytokines such as IL-1 $\beta$ that account for important paracrine actions mediated by CAFs toward BC growth and dissemination (Pandey et al., 2009; De Francesco et al., 2013, 2014, 2017, 2018a; Pupo et al., 2014; Ren et al., 2015; De
Marco et al., 2016; Santolla et al., 2019; Lappano et al., 2020b). Interestingly, diverse studies have shown that GPER bridges together estrogenic signaling with IGF1R and IR-mediated action in the breast tumor microenvironment, independent of the ER status. For instance, the IGF-1/IGF-1R pathway triggers the up-regulation of GPER through the PKC $\delta / E R K / c$-fos/AP1 transduction cascade in an $\mathrm{ER} \alpha$-dependent manner, leading to migratory effects in MCF7 BC cells (De Marco et al., 2013). The cross-talk between IGF-1R and GPER appears to represent a general stimulatory mechanism shared among diverse types of cancer, including mesothelioma and lung cancer (Avino et al., 2016). In addition, IGF-1 stimulation prompted a crosstalk between GPER and DDR-1 leading to cell migration and chemotaxis (Avino et al., 2016). In ER-negative breast CAFs, GPER was shown to be necessary for the stimulatory actions triggered by the metal zinc through the IGF-1R pathway toward CAFs and BC cell migration (Pisano et al., 2017). Furthermore, a functional interaction between GPER and HIF- $1 \alpha$ triggered the IGF-1-mediated release of VEGF by CAFs, which prompted vessel-like assembly in endothelial cells. Altogether, these findings suggest that a complex network between ER, GPER, and IGF-1R stimulates the tumor microenvironment and especially CAFs to facilitate metastatic spread. Extending these findings, GPER was shown to be up-regulated not only by IGF-1 but also by insulin in both BC cells and CAFs, thus indicating that GPER may be included among the transduction mediators engaged by the IIGFs pathway in BC (De Marco et al., 2014). The positive correlation between GPER expression in CAFs and serum levels of insulin in $\mathrm{BC}$ patients further corroborates the role of insulin in promoting a dysfunctional microenvironment toward disease progression. It should be mentioned that both GPER and the IIGFs have been implicated in the aberrant activation of EMT programs (Table 1), which are known to promote metastasis initiation through multiple mechanisms, such as the gain of stemness properties. In this context, GPER was shown to trigger $\beta 1$-integrin expression, leading to CAF-induced cell migration and EMT (Yuan et al., 2015). Likewise, estrogenic GPER signaling promoted EMT through the activation of the Notch pathway (Pupo et al., 2014), a signaling system involved in CSC maintenance and survival (De Francesco et al., 2018a). Moreover, in patient-derived xenografts from ER-negative BCs, GPER expression was shown to be higher in breast CSCs compared to the non-CSC counterpart (Chan et al., 2020); phosphoproteomic analysis identified the PKA and BAD-Ser118 as the main transduction mediators involved in GPER signaling in breast CSCs (Chan et al., 2020). Interestingly, GPER silencing reduced CSCs activity in vitro and tumor growth in vivo (Chan et al., 2020), thus reinforcing the involvement of this receptor in CSC functionality.

Despite the role of estrogenic GPER signaling in regulating breast CSC biology has been recently acknowledged, the contribution of ERs in both normal and CSC remains controversial (Sleeman et al., 2007). Indeed, estrogens appear to rely on receptors others than the classic $\mathrm{ER} \alpha$ for the expansion of populations with stem-like features (Fillmore et al., 2010; Alferez et al., 2018). In this context, it should be mentioned that the ER target gene PR plays a key role in the regulation of stemness as evidenced in normal mammary gland 
development, as well as in the context of breast neoplasia (Daniel and Lange, 2009; Axlund and Sartorius, 2012; Hilton et al., 2012; Finlay-Schultz and Sartorius, 2015; Knutson et al., 2017; Truong et al., 2019).

Likewise, the early dissemination of $\mathrm{PR}^{+} \mathrm{BC}$ cells has been demonstrated using animal models of BC (Hosseini et al., 2016). Extending these findings, PR signaling has been shown to synergize with ER pathway to regulate a number of effectors involved in stemness, metastatic proficiency, and resistance to therapy (Hilton et al., 2012; Finlay-Schultz and Sartorius, 2015; Mohammed et al., 2015; Diep et al., 2016). Among these mediators, the PR target gene insulin receptor substrate 1 (IRS1 ), which is a relevant member of the IIGFs, may represent a novel node, bridging together ER-signaling and IIGF signaling by means of PR (Daniel and Lange, 2009).

As it concerns the IGF system, IGF-1R represents a very wellknown driver of EMT and stem-related functions in normal and cancerous tissues. Stem-promoting signaling pathways such as Notch, Wnt/ $\beta$-catenin and Shh may function upstream of IGF-1R to increase its expression (reviewed in Farabaugh et al., 2015): in addition, signaling cascades downstream of IGF-1R activate transcription factors involved in the control of EMT and stemness, such as Zeb1, NF- $\kappa$ B, Snail, Twist, Sox2, Oct4, Nanog (reviewed in Farabaugh et al., 2015). It has been reported that IGF-1 signaling has a critical role in $\mathrm{BC}$ progression by controlling both the maintenance of BCSCs and their EMT behavior (Chang et al., 2013). However, IGF1 can enable EMT also through the activation of non-classical EMT factors; this is the case for transmembrane glycoprotein MUC1, which is frequently overexpressed in BC metastasis, and is up-regulated through the IGF-1R/PI3K/AKT pathway (Cordone et al., 2017). Intriguingly, targeting MUC1 may reverse BC stem cell phenotype, thereby supporting the role of MUC1 in metastatic dissemination. The mammary tissue is rich in adipocytes that produce multiple endocrine, inflammatory, and angiogenic factors involved in the growth and the acquisition of malignant and stem cell traits by adjacent breast tumor cells (Lee et al., 2015). Accordingly, a number of experimental evidences have supported the role of adipocytes in the establishment of metastasis in BC (Kamat et al., 2015). As mentioned above, estrogen production in adipocytes could be one of the mechanisms involved in the higher incidence and aggressiveness of $\mathrm{BC}$ observed in obese postmenopausal women. It is been demonstrated that aromatase activity in differentiated adipocytes, as well as in adipose stem cells, is fostered by the hormone leptin, as well as by other adipokines such as IL-6, with the result to increase local estrogen production and $\mathrm{ER} \alpha$ signaling (Liu et al., 2013; Strong et al., 2013; Sabol et al., 2019). Beyond estrogen production, other obesity-related factors can contribute to the acquisition of metastatic phenotypes in BC patients. For instance, obesity is associated with a low-grade chronic inflammatory state, characterized by increased production of inflammatory mediators, together with enhanced IGF-1 and insulin signaling (Iyengar et al., 2013). In this context, it should be mentioned that inflammatory factors produced by adipose cells subjected to fat overload contribute not only to insulin resistance, but also to increased metastatic propensity. In conditions of obesity, the adipose tissue is highly inflammogenic as the stressed adipocytes undergo hypoxia and eventually death, thereby liberating several signaling molecules from dying cells. These damage-associated molecular patterns in turn attract immune cells such as macrophages, which enwrap dying adipocytes to form crown-like structures and foam cells. Inflammatory cytokines such as TNF- $\alpha$, IFN- $\gamma$, IL-1 $\beta$, IL- 6 , and HMGB1 are released either by adipocytes or activated macrophages to recall additional immune cells and perpetuate the inflammatory damage. Certain inflammatory mediators secreted from the adipose tissue of breast tumors have been shown to trigger direct stimulatory effects on BC cells. For instance, the migration rate of BC cells was increased after coculture with carcinoma adipose stromal cells; this effect was shown to be dependent on the up-regulation of the small calcium binding protein and inflammatory mediator named S100A7, which is correlated with adverse pathological parameters and poor relapse-free survival (Sakurai et al., 2017). Likewise, oncostatin M (OSM) and other adipokines released from tumorassociated adipose tissue prompted the activation of STAT3, and its target genes S100A7, S100A8, and S100A9 triggering increased cellular scattering and peritumoral neovascularization of orthotopic xenografts (West and Watson, 2010; Lapeire et al., 2014). Adding to this, cytokines such as IL-6, IL-1 $\beta$, and TNF$\alpha$, as well as adipokines such as leptin and adiponectin released by bone marrow adipocytes, send homing signals for BC cells to colonize the bone tissue (Choi et al., 2018a). Thereafter, the process of metastasis priming at distant site can be facilitated by a number of adipocyte-derived paracrine factors whose expression is often regulated by both estrogens and IIGFs. This is the case for IL- $1 \beta$, which is a transcriptional target of signals mediated by GPER (De Marco et al., 2016), ER (Ruh et al., 1998), and IGF-1R (Ho et al., 2017) toward increased invasiveness and metastatic aggressiveness (De Marco et al., 2016; Eyre et al., 2019). In addition, IL-1 $\beta$ is involved in the activation of obesity-induced insulin resistance and inflammation. In fact, reduced gene expression, protein abundance of insulin signaling molecules, and increased release of inflammatory mediators were observed in adipocytes stimulated with IL-1 $\beta$ (Gao et al., 2014). Furthermore, IL1- $\beta$ was shown to promote stem-cell-like phenotypes and invasiveness in MCF7 BC cell through the upregulation of IL-6 (Oh et al., 2016), which has been shown to be released not only by cancer cells but also by adipocytes, CAFs, and TAMs (Gyamfi et al., 2018; Xu et al., 2019). Beyond the ability to promote the release of proinflammatory molecules such as IL-1 $\beta$ and IL-6 in the tumor microenvironment, estrogens and IIGFsmediated signals have been shown to cross-communicate with certain adipokines such as leptin. As mentioned previously, leptin increases the availability of estrogens and promotes migration, invasion, EMT, and CSC enrichment in BC (Strong et al., 2015). A well-documented cross-talk between leptin and IGF-1R signaling pathways has been shown to promote the migration and invasion of BC cells (Saxena et al., 2008). Furthermore, leptin pathway cooperates with ER-mediated signaling to trigger stimulatory actions in BC (Fusco et al., 2010).

TAMs may comprise up to $50 \%$ of the BC microenvironment (Obeid et al., 2013). TAMs regulate the secretion of growth factors, proinflammatory cytokines and chemokines leading 
to the resistance to endocrine therapy, tissue remodeling, angiogenesis, suppression of immune responses, and tumor growth (Obeid et al., 2013). Consequently, TAMs are associated with an increased aggressiveness and worse outcomes in breast malignancy (Williams et al., 2016; Choi et al., 2018b). For instance, TAMs may induce tamoxifen resistance through the activation of the PI3K/Akt/mTOR transduction pathway in BC cells (Li et al., 2020). Likewise, macrophage differentiation in TAMs mediated by the Notch signaling may promote $\mathrm{BC}$ resistance to the aromatase inhibitors (Liu et al., 2017). Interestingly, $\mathrm{BC}$ cells exposed to conditioned medium from TAMs have been shown to exhibit loss of ER $\alpha$ expression, increase of the proliferative marker $\mathrm{Ki67}$, and the activation of c-Src, PKC, and MAPK transduction pathways, further supporting a role for TAMs in the endocrine resistance and BC patients' prognosis (Stossi et al., 2012). Together with CAFs, TAMs are the main source of IGFs within both primary and metastatic tumors. High macrophage infiltration has been associated with a poor prognosis and increased rates of metastasis in several cancer types, as TAMs can facilitate blood vessel formation to support expanding tumor growth and aid tumor cell intravasation into vasculature (Chittezhath et al., 2014). Soluble factors present in the TME, such as IGFs, may recruit and influence macrophage behavior (Hao et al., 2012). For instance, macrophages have been shown to play a role in matrix organization through the secretion of MMPs that are capable to degrade and reorganize the matrix, as well as aid in tumor cell migration (Kessenbrock et al., 2010). Moreover, TAMs have been shown to facilitate the deposition of aligned collagen fibers during tumor development (Varol, 2019). The binding of these ECM proteins to adhesion receptors on the surface of macrophages promotes inflammatory and tumor-promoting macrophage activation (Hsieh et al., 2017). Alterations in ECM organization and composition in the tumor microenvironment result in increased matrix stiffness, primarily localized at the invasive front of breast tumors. These stiff regions are enriched in aligned collagen fibers and TAMs. Studies have demonstrated that substrate stiffness, which is associated with enhanced breast tumor progression, is another mechanical aspect of the ECM that can influence macrophage behavior. Matrix stiffness, increasing CCL2 levels, may recruit specific macrophage populations, which interact with collagen fibers and facilitate tumor cell dissemination. Thus, it is becoming clear that macrophages are sensitive to changes in the ECM and their mechanical environment. In agreement, activation of IIGFs in BC patients has been correlated with increased macrophage infiltration, advanced tumor stage, resistance to therapies, and poor prognosis (Campbell et al., 2011). Stroma-derived IGFs have been further investigated in $\mathrm{BC}$ progression and metastasis, and the therapeutic opportunity of blocking IIGFs in combination with chemotherapy has been also evaluated. For instance, the efficacy of paclitaxel, a chemotherapeutic agent commonly used for the treatment of invasive $\mathrm{BC}$, has been shown to be increased by the concomitant block of IGFs (Ireland et al., 2018). Altogether, these findings indicate that estrogens and IIGFs may cooperate to elicit a multifaceted breast tumor-supporting action through CAFs, tumor-associated adipocytes and macrophages, and other
TABLE 3 | Main combination therapies targeting the IIGFs and estrogen signaling.

\begin{tabular}{|c|c|c|}
\hline \multicolumn{2}{|c|}{ Combination therapies targeting } & \multirow{2}{*}{$\begin{array}{l}\text { References or } \\
\text { ClinicalTrials.gov identifiers }\end{array}$} \\
\hline IIGFs & Estrogens & \\
\hline Figitumumab & Exemestane & Ryan et al., 2011 \\
\hline Ganitumab & Exemestane or fulvestrant & Robertson et al., 2013 \\
\hline Linsitinib & Letrozole & NCT01205685 \\
\hline MEDI-573 & $\begin{array}{l}\text { Letrozole, anastrozole, or } \\
\text { exemestane }\end{array}$ & NCT01446159 \\
\hline
\end{tabular}

important components of the tumor stroma. By shaping relevant paracrine interactions within the tumor microenvironment, estrogen and IIGFs signaling systems may play a key role in the development and progression of BC metastasis.

\section{MANIPULATING THE CROSS-TALK BETWEEN ESTROGENIC SIGNALS AND IIGF TO HALT METASTATIC PROGRESSION}

Hormone therapy targeting the ER-mediated pathway is largely used for ER-positive breast tumors, which account for approximately $75 \%$ of all BCs (Senkus et al., 2013). Despite the good outcome, certain ER-positive tumors may become resistant to treatments and relapse, leading to a poor prognosis (Osborne and Schiff, 2011; Ma C.X. et al., 2015). Multiple mechanisms responsible for the endocrine resistance have been proposed including the activation of escape pathways toward alternate proliferative and survival stimuli (Osborne and Schiff, 2011; Ma C.X. et al., 2015). In this vein, diverse BC subtypes commonly express high levels of main players of IIGFs (Bhargava et al., 2011; Bahhnassy et al., 2015). Therefore, targeting IIGFs has been suggested as a promising therapeutic approach in BCs (Christopoulos et al., 2018). Accordingly, many components of the IGFs have been indicated as suitable targets on the basis of the results obtained in preclinical studies (Motallebnezhad et al., 2016). Unfortunately, clinical trials, particularly phase III studies, performed in BC patients, provided rather disappointing data for the rise of adverse effects together with minimal clinical benefit (Philippou et al., 2017; Qu et al., 2017). Hence, strategies cotargeting the bidirectional network between the estrogen and IIGFs could be exploited toward successful treatments (Table 3). In this regard, in a clinical trial for advanced ER-positive BCs, the use of the IGF-1R Ab figitumumab combined with the aromatase inhibitor exemestane has provided encouraging results in patients without preexisting metabolic syndrome at the time of the enrollment (Ryan et al., 2011). On the contrary, the addition of the IGF-1R therapeutic monoclonal $\mathrm{Ab}$ ganitumab to exemestane or fulvestrant did not improve the outcomes (Robertson et al., 2013). Moreover, experimental findings indicating an increased ratio of IR-A:IR-B in ERpositive BCs (luminal B) have suggested that targeting both IR-A and IGF-1R, along with the estrogen signaling, may be 
beneficial in these patients, therefore avoiding the compensatory cross-talk between IGF-1R and IR (Huang et al., 2011; Yee, 2012). In this regard, a phase II study (NCT01205685) investigated in ER-positive BC patients the potential antitumor activity of a dual IGF-1R/IR tyrosine kinase inhibitor, namely, linsitinib (OSI906), used in combination with hormone therapy. Unfortunately, this study was ended because of the appearance of severe toxicities associated with the treatments. To date, much focus has been turned into the design of novel molecules showing an enhanced efficacy without adverse effects and the identification of natural compounds able to trigger the desired action. Picropodophyllotoxin (PPT) is an epimer of podophyllotoxin isolated from the roots of Podophyllum hexandrum, which has been used as an antitumor drug and insecticidal/antifungal agent (Liu et al., 2015; Zhi et al., 2017). Launched as an anticancer drug targeting specifically the IGF-1R autophosphorylation (Girnita et al., 2004), PPT was shown to prevent the paracrine recruitment of fibroblasts and their activation as CAFs by breast tumor cells expressing c-Myc (De Vincenzo et al., 2019). PPT was also evidenced to suppress the capacity of $\mathrm{CD} 24^{-} \mathrm{CD} 44^{+} \mathrm{BC}$ stem cells to undergo the EMT process (Chang et al., 2013). Promising experimental data have been provided using a dual IGF-1R/IR tyrosine kinase inhibitor, named BMS-536924, which showed the capability to prevent proliferative and migratory features of BC cells (Law et al., 2008; Litzenburger et al., 2009), without adverse effects associated with the insulin deficiency (Dool et al., 2011). Furthermore, a tyrosine kinase inhibitor targeting both IGF-1R and IR, named BMS-754807, triggered an inhibitory response in TNBC cells characterized by an IGF signature (Litzenburger et al., 2011). Likewise, TNBC cells derived from mice inoculated with both cancer cells and mesenchymal stem cells exhibited a reduced formation of bone metastasis using the BMS-754807 (Zhang et al., 2013). Unfortunately, clinical evidence regarding the action of both BMS-536924 and BMS-754807 in breast tumors, either using each inhibitor alone or in combination with hormone therapeutics, is still lacking. The interaction of tumor cells with the surrounding stroma profoundly influences the etiology and progression of $\mathrm{BC}$ through multiple mediators including hormones, growth factors, and cytokines. For instance, tumor-stroma communications may provide within the breast microenvironment growth factors such as IGFs, which in turn activate the ER-mediated signaling (Bartella et al., 2012). Similarly, the alternate ER GPER interacts with the IGF-1R transduction pathways acting as a mediator of the multifaceted estrogen action on breast CAFs (De Marco et al., 2013, 2014, 2016; Lappano et al., 2013; De Francesco et al., 2017; Pisano et al., 2017). Together, novel therapeutic approaches targeting the tumorstroma network are required in order to inhibit the various molecules secreted within the tumor microenvironment and the downstream pathways prompting the proliferation, invasion, and resistance to chemotherapy of the tumor cells. In this context, size-switchable nanoparticles that deliver chemotherapeutics and simultaneously halt the stimulatory action of important regulators of the cancer microenvironment have been proposed in order to improve the treatment outcomes (Cun et al., 2019). As a therapeutic option in $\mathrm{BC}$, an approach targeting downstream effectors of the cross-talk occurring between estrogen and IIGFs has been also suggested. Among others, valuable candidates are the inhibitors of the PI3K pathway (Jia et al., 2008), which is mainly involved in the IGF-1R-mediated action (Ciruelos Gil, 2014; Kasprzak et al., 2017). Moreover, a cross-talk between the $\mathrm{PI} 3 \mathrm{~K} / \mathrm{AKT} / \mathrm{mTOR}$ and the ER transduction cascades may occur either directly or through the IGF-1R effector, namely, IRS1 (Guvakova and Surmacz, 1997; Ciruelos Gil, 2014). Hence, this latter mediator could be considered as a further potential target of the estrogen and IGFs network in BC. Indeed, IRSs are adapter proteins that interact with both IR and IGF-1R toward the stimulation of cell growth, motility, and metastasis (Pirola et al., 2003; Becker et al., 2016). Serving as scaffolds in BC cells, IRSs activate other intermediate proteins including the PI3K/AKT/mTOR signaling (Law et al., 2008; Mirdamadi et al., 2015). Of note, estrogens trigger the up-regulation of IRS- 1 activating the PI3K transduction pathway (Guvakova and Surmacz, 1997; Sisci et al., 2007). Accordingly, the silencing of IRS-1 enhanced the tamoxifen-induced cell death in BC cells (Cesarone et al., 2006) and abrogated the transcriptional activity of ER dependent by IGF-1 (Sisci et al., 2007).

Because of the multilevel paracrine actions elicited by both IGF-1 and IGF-2 in BC metastasis, it is plausible to hypothesize that the direct targeting of IGF-1 and/or IGF-2 would provide an interesting strategy in therapeutic setting. The ligandneutralizing approach has been tested in preclinical and clinical studies in diverse types of solid tumors, including BC. For instance, the neutralizing human $\mathrm{Ab}$ MEDI-573 serves as a double inhibitor for IGF-1 and IGF-2. In animal models, MEDI573 blocks tumor growth by halting the IGF-1R and IR-A signaling cascade (Iguchi et al., 2015). Because of the encouraging results, MEDI-573 is currently under investigation in a phase $1 \mathrm{~b} / 2$ clinical trial in patients with metastatic $\mathrm{HR}^{+} / \mathrm{HER} 2^{-}$ BC, in combination with aromatase inhibitors (NCT01446159). Preliminary data have shown that MEDI-573 suppresses IGF-1 and IGF-2 without generating dose-limiting toxicity including metabolic disorders (Iguchi et al., 2015). The monoclonal Ab neutralizing IGF-1 and IGF-2 named BI836845 is also being tested in a cohort of $\mathrm{HR}^{+} / \mathrm{HER} 2^{-}$metastatic BC patients, in combination with mTOR and aromatase inhibitors, in a phase 2 clinical trial (NCT02123823). Furthermore, Vaniotis et al. (2018) generated a soluble fusion protein consisting of the extracellular domain of human IGF-1R and the Fc domain of human IgG. This product, named IGF-TRAP, showed IGF-1 and IGF-2-binding activity with elevated affinity, which was threefold higher than that of insulin (Vaniotis et al., 2018). The IGFTRAP exhibited potent anti-antimetastatic bioactivity in BC, thus representing a novel tool for better manipulation of metastatic disease (Vaniotis et al., 2018).

Strategies cotargeting both estrogen and the IGF signaling as well as the cross-communication with protumorigenic molecules such as the adipokine leptin or the proinflammatory cytokine IL1- $\beta$ would appear to offer major beneficial effects with respect to the inhibition of a single signaling pathway. In this vein, it should be mentioned that leptin inhibition reversed the breast CSC phenotype (Giordano et al., 2016), as well as lessened the effects exerted by adipose-derived stem cells (ASCs) derived from obese BC patients on cancer cell growth (Strong et al., 
2013). Approved by the US Food and Drug Administration for the treatment of rheumatoid arthritis, the IL-1 antagonist anakinra showed in $\mathrm{BC}$ a remarkable safety record together with a suppressive action on the IL-1-related inflammatory effects ( $\mathrm{Wu}$ et al., 2018). To date, a single pilot trial aimed at determining the safety of anakinra used along with chemotherapy in patients with metastatic BCs is currently undergoing (NCT01802970). Overall, these findings may suggest that investigating the potential of combination strategies might provide further cues and clinical advantages in $\mathrm{BC}$ patients.

\section{DISCUSSION}

Metastatic BCs continue to be a foremost challenge as they are almost always incurable, ultimately leading to death (DeSantis et al., 2019). The poor clinical prognosis is further exacerbated by the lack of effective targeted treatments and by acquired resistance to therapies. Notwithstanding the advances made with targeted therapies, the absence of defined molecular targets and the high tumor heterogeneity of metastatic BC have resulted in lack of benefit in several subgroups of these patients (Mutebi et al., 2020). The discovery of new molecular targeting agents for metastatic BC is therefore an unmet need. Metastatic disease and therapy resistance are highly correlated with intracellular activated pathways. While previous studies have been mainly focused on genetic and biological differences between primary and metastatic epithelial BC cells, more recently, attention has gradually shifted to the most important cellular components of tumor stroma ascribing an increasing importance to cells of tumor microenvironment (Hanahan and Coussens, 2012; Guo and Deng, 2018). During cancer progression, both malignant epithelial and stromal cells produce various components and/or remodelers of ECM that promote metastatic progression, establishing the concept that tumor microenvironment has an essential role in $\mathrm{BC}$ biology and therapeutic response (Hanahan and Coussens, 2012; Guo and Deng, 2018). Extensive differences in tumor stroma compared with normal stroma have been widely observed, and several studies have shown that tumor microenvironment may affect biology and progression of cancer cells influencing therapeutic response and clinical outcome (Cacho-Díaz et al., 2020). Differences in tumor microenvironment of primary tumor and metastatic lesions have been reported. For instance, tumor cells are more protected in metastatic lesions than in primary tumor by tumor microenvironment (Cacho-Díaz et al., 2020). Soluble factors secreted by tumor or stromal cells, as well as ligand-receptor interactions and downstream pathways activation, play a pivotal role. Thus, we can expect that the full comprehension of underneath defects could be precious in future therapeutic perspectives.

The importance of IIGFs and estrogenic signaling in BC is well-established, as is the cross-talk between these pathways. However, relatively little is known regarding the impact of this cross-talk in modulating BC cells/microenvironment interactions, especially regarding $\mathrm{BC}$ metastatic evolution. We have focused on evidence showing that, indeed, estrogen/IIGFs impacts on stroma at different levels and that, conversely, tumor stroma itself is a main source of soluble and non-soluble secreted molecules, which regulate ECM remodeling, neoangiogenesis, migration, and invasion. In particular, dysregulated expression and bioavailability of IGFs have been implicated in key stages of metastasis, while estrogenic signaling toward the development of breast malignant features (Bartella et al., 2012; De Marco et al., 2015). Noteworthy, estrogen production by adipocytes has been linked to the higher incidence and aggressiveness of BC in obese postmenopausal women (Park et al., 2017).

Hopefully, a better knowledge of the impact of the estrogen/IIGFs cross-talk in modulating BC metastasis by affecting tumor microenvironment could have translational implications. Interestingly, IIGFs is regulated by ER but becomes the reliant signaling pathway when the expression and activation of ER are lowered by long-term blockade of ER signaling. In parallel, GPER signaling, which contributes to tamoxifen resistance, is crucially involved in a bidirectional cross-talk with IIGFs (Bartella et al., 2012; De Marco et al., 2015).

As already mentioned, IIGFs and estrogen signaling pathways are molecularly interconnected and result in redundancies and compensations that contribute to BC aggressiveness. Consistently, IIGFs inhibition have been exploited to overcome $\mathrm{BC}$ resistance and improve clinical outcome; however, an ideal way to inhibit IGF-1R, IR-A, and hybrid IR-A in cancer is still lacking. To date, several potential strategies against IIGFs and estrogen system activation have been attempted, but targeting a single system has failed to improve clinical outcome. Definitely, we propose that a combined approach strategy is mandatory.

In summary, we believe that targeting the tumor-environment interaction by focusing on the estrogen-IIGFs cross-talk may represent an effective therapeutic option, especially in patients with hyperinsulinemia due to insulin resistance. However, further studies are still needed to explore this challenging therapeutic option.

\section{AUTHOR CONTRIBUTIONS}

$\mathrm{VV}, \mathrm{ED}$, and RL collected and discussed the literature and wrote the manuscript, in collaboration with MGM and LM. AB and $\mathrm{MM}$ coordinated the work, and substantially integrated the manuscript, which was revised and approved, in its final version, by all authors. All authors contributed to the conceptualization and design of the review.

\section{FUNDING}

Fondazione AIRC supported AB (IG n. 23369), MM (IG n. 21322), and ED (Start-Up Grant 21651). RL and MM acknowledge (i) the special award namely "Department of Excellence 2018-2022" (Italian Law 232/2016) to the Department of Pharmacy, Health and Nutritional Sciences of the University of Calabria (Italy), (ii) the "Sistema Integrato di Laboratori per L'Ambiente - (SILA) PONa3_00341.” 


\section{REFERENCES}

Aceto, N., Bardia, A., Miyamoto, D. T., Donaldson, M. C., Wittner, B. S., Spencer, J. A., et al. (2014). Circulating tumor cell clusters are oligoclonal precursors of breast cancer metastasis. Cell 158, 1110-1122. doi: 10.1016/j.cell.2014.07.013

Alba-Castellón, L., Olivera-Salguero, R., Mestre-Farrera, A., Peña, R., Herrera, M., Bonilla, F., et al. (2016). Snail1-dependent activation of cancer-associated fibroblast controls epithelial tumor cell invasion and metastasis. Cancer Res. 76, 6205-6217. doi: 10.1158/0008-5472.CAN-16-0176

Alferez, D. G., Simões, B. M., Howell, S. J., and Clarke, R. B. (2018). The Role of steroid hormones in breast and effects on cancer stem cells. Curr. Stem Cell Rep. 4, 81-94. doi: 10.1007/s40778-018-0114-z

Ao, Z., Shah, S. H., Machlin, L. M., Parajuli, R., Miller, P. C., Rawal, S., et al. (2015). Identification of cancer-associated fibroblasts in circulating blood from patients with metastatic breast cancer. Cancer Res. 75, 4681-4687. doi: 10.1158/00085472.CAN-15-1633

Auricchio, F., Migliaccio, A., and Castoria, G. (2008). Sex-steroid hormones and EGF signalling in breast and prostate cancer cells: targeting the association of Src with steroid receptors. Steroids 73, 880-884. doi: 10.1016/j.steroids.2008.01. 023

Avino, S., De Marco, P., Cirillo, F., Santolla, M. F., De Francesco, E. M., Perri, M. G., et al. (2016). Stimulatory actions of IGF-I are mediated by IGF-IR cross-talk with GPER and DDR1 in mesothelioma and lung cancer cells. Oncotarget 7, 52710-52728. doi: 10.18632/oncotarget. 10348

Awolaran, O., Brooks, S. A., and Lavender, V. (2016). Breast cancer osteomimicry and its role in bone specific metastasis; an integrative, systematic review of preclinical evidence. Breast Edinb. Scotl. 30, 156-171. doi: 10.1016/j.breast. 2016.09.017

Axlund, S. D., and Sartorius, C. A. (2012). Progesterone regulation of stem and progenitor cells in normal and malignant breast. Mol. Cell Endocrinol. 357, 71-79. doi: 10.1016/j.mce.2011.09.021

Bahhnassy, A., Mohanad, M., Shaarawy, S., Ismail, M. F., El-Bastawisy, A., Ashmawy, A. M., et al. (2015). Transforming growth factor- $\beta$, insulin-like growth factor I/insulin-like growth factor I receptor and vascular endothelial growth factor-A: prognostic and predictive markers in triple-negative and nontriple-negative breast cancer. Mol. Med. Rep. 12, 851-864. doi: 10.3892/mmr. 2015.3560

Ballaré, C., Uhrig, M., Bechtold, T., Sancho, E., Di Domenico, M., Migliaccio, A., et al. (2003). Two domains of the progesterone receptor interact with the estrogen receptor and are required for progesterone activation of the c-Src/Erk pathway in mammalian cells. Mol. Cell Biol. 23, 1994-2008. doi: 10.1128/MCB. 23.6.1994-2008.2003

Bar, R. S., and Boes, M. (1984). Distinct receptors for IGF-I, IGF-II, and insulin are present on bovine capillary endothelial cells and large vessel endothelial cells. Biochem. Biophys. Res. Commun. 124, 203-209. doi: 10.1016/0006-291X(84) 90937-9

Bartella, V., De Marco, P., Malaguarnera, R., Belfiore, A., and Maggiolini, M. (2012). New advances on the functional cross-talk between insulin-like growth factor-I and estrogen signaling in cancer. Cell Signal. 24, 1515-1521. doi: 10.1016/j.cellsig.2012.03.012

Barton, M., Filardo, E. J., Lolait, S. J., Thomas, P., Maggiolini, M., and Prossnitz, E. R. (2018). Twenty years of the G protein-coupled estrogen receptor GPER: historical and personal perspectives. J. Steroid. Biochem. Mol. Biol. 176, 4-15. doi: 10.1016/j.jsbmb.2017.03.021

Becker, M. A., Ibrahim, Y. H., Oh, A. S., Fagan, D. H., Byron, S. A., Sarver, A. L., et al. (2016). Insulin receptor substrate adaptor proteins mediate prognostic gene expression profiles in breast cancer. PLoS One 11:e0150564. doi: 10.1371/ journal.pone. 0150564

Belfiore, A., Frasca, F., Pandini, G., Sciacca, L., and Vigneri, R. (2009). Insulin receptor isoforms and insulin receptor/insulin-like growth factor receptor hybrids in physiology and disease. Endocr. Rev. 30, 586-623. doi: 10.1210/er. 2008-0047

Belfiore, A., and Malaguarnera, R. (2011). Insulin receptor and cancer. Endocr. Relat. Cancer 18, R125-R147. doi: 10.1530/ERC-11-0074

Belfiore, A., Malaguarnera, R., Vella, V., Lawrence, M. C., Sciacca, L., Frasca, F., et al. (2017). Insulin receptor Isoforms in physiology and disease: an updated view. Endocr. Rev. 38, 379-431. doi: 10.1210/er.2017-00073
Belfiore, A., Pandini, G., Vella, V., Squatrito, S., and Vigneri, R. (1999). Insulin/IGF-I hybrid receptors play a major role in IGF-I signaling in thyroid cancer. Biochimie 81, 403-407. doi: 10.1016/S0300-9084(99)80088-1

Bhargava, R., Beriwal, S., McManus, K., and Dabbs, D. J. (2011). Insulin-like growth factor receptor-1 (IGF-1R) expression in normal breast, proliferative breast lesions, and breast carcinoma. Appl. Immunohistochem. Mol. Morphol. AIMM 19, 218-225. doi: 10.1097/PAI.0b013e3181ffc58c

Bielenberg, D. R., and Zetter, B. R. (2015). The contribution of angiogenesis to the process of metastasis. Cancer J. 21, 267-273. doi: 10.1097/PPO. 0000000000000138

Bjorndahl, M., Cao, R., Nissen, L. J., Clasper, S., Johnson, L. A., Xue, Y., et al. (2005). Insulin-like growth factors 1 and 2 induce lymphangiogenesis in vivo. Proc. Natl. Acad. Sci. U.S.A. 102, 15593-15598. doi: 10.1073/pnas.0507865102

Björnström, L., and Sjöberg, M. (2005). Mechanisms of estrogen receptor signaling: convergence of genomic and nongenomic actions on target genes. Mol. Endocrinol. 19, 833-842. doi: 10.1210/me.2004-0486

Bouris, P., Skandalis, S. S., Piperigkou, Z., Afratis, N., Karamanou, K., Aletras, A. J., et al. (2015). Estrogen receptor alpha mediates epithelial to mesenchymal transition, expression of specific matrix effectors and functional properties of breast cancer cells. Matrix Biol. 43, 42-60. doi: 10.1016/j.matbio.2015.02.008

Cacho-Díaz, B., García-Botello, D. R., Wegman-Ostrosky, T., Reyes-Soto, G., Ortiz-Sánchez, E., and Herrera-Montalvo, L. A. (2020). Tumor microenvironment differences between primary tumor and brain metastases. J. Transl. Med. 18:1. doi: 10.1186/s12967-019-02189-8

Campbell, M. J., Tonlaar, N. Y., Garwood, E. R., Huo, D., Moore, D. H., Khramtsov, A. I., et al. (2011). Proliferating macrophages associated with high grade, hormone receptor negative breast cancer and poor clinical outcome. Breast Cancer Res. Treat. 128, 703-711. doi: 10.1007/s10549-010-1154-y

Castoria, G., Migliaccio, A., Bilancio, A., Di Domenico, M., de Falco, A., Lombardi, M., et al. (2001). PI3-kinase in concert with Src promotes the S-phase entry of oestradiol-stimulated MCF-7 cells. EMBO J. 20, 6050-6059. doi: 10.1093/ emboj/20.21.6050

Castoria, G., Migliaccio, A., Di Domenico, M., Lombardi, M., de Falco, A., Varricchio, L., et al. (2004). Role of atypical protein kinase C in estradioltriggered G1/S progression of MCF-7 cells. Mol. Cell Biol. 24, 7643-7653. doi: 10.1128/MCB.24.17.7643-7653.2004

Cesarone, G., Garofalo, C., Abrams, M. T., Igoucheva, O., Alexeev, V., Yoon, K., et al. (2006). RNAi-mediated silencing of insulin receptor substrate 1 (IRS-1) enhances tamoxifen-induced cell death in MCF-7 breast cancer cells. J. Cell Biochem. 98, 440-450. doi: 10.1002/jcb.20817

Chan, Y.-T., Lai, A. C.-Y., Lin, R.-J., Wang, Y.-H., Wang, Y.-T., Chang, W.-W., et al. (2020). GPER-induced signaling is essential for the survival of breast cancer stem cells. Int. J. Cancer 146, 1674-1685. doi: 10.1002/ijc.32588

Chang, W.-W., Lin, R.-J., Yu, J., Chang, W.-Y., Fu, C.-H., Lai, A. C.-Y., et al. (2013). The expression and significance of insulin-like growth factor-1 receptor and its pathway on breast cancer stem/progenitors. Breast Cancer Res. 15:R39. doi: $10.1186 /$ bcr 3423

Charafe-Jauffret, E., Ginestier, C., Iovino, F., Wicinski, J., Cervera, N., Finetti, P., et al. (2009). Breast cancer cell lines contain functional cancer stem cells with metastatic capacity and a distinct molecular signature. Cancer Res. 69, 1302-1313. doi: 10.1158/0008-5472.CAN-08-2741

Chittezhath, M., Dhillon, M. K., Lim, J. Y., Laoui, D., Shalova, I. N., Teo, Y. L., et al. (2014). Molecular profiling reveals a tumor-promoting phenotype of monocytes and macrophages in human cancer progression. Immunity 41, 815-829. doi: 10.1016/j.immuni.2014.09.014

Choi, J., Cha, Y. J., and Koo, J. S. (2018a). Adipocyte biology in breast cancer: from silent bystander to active facilitator. Prog. Lipid Res. 69, 11-20. doi: 10.1016/j.plipres.2017.11.002

Choi, J., Gyamfi, J., Jang, H., and Koo, J. S. (2018b). The role of tumor-associated macrophage in breast cancer biology. Histol. Histopathol. 33, 133-145.

Christopoulos, P. F., Corthay, A., and Koutsilieris, M. (2018). Aiming for the Insulin-like Growth Factor-1 system in breast cancer therapeutics. Cancer Treat. Rev. 63, 79-95. doi: 10.1016/j.ctrv.2017.11.010

Chung, Y.-L., Sheu, M.-L., Yang, S.-C., Lin, C.-H., and Yen, S.-H. (2002). Resistance to tamoxifen-induced apoptosis is associated with direct interaction between Her2/neu and cell membrane estrogen receptor in breast cancer. Int. J. Cancer 97, 306-312. doi: 10.1002/ijc.1614 
Cirillo, F., Lappano, R., Bruno, L., Rizzuti, B., Grande, F., Guzzi, R., et al. (2019). AHR and GPER mediate the stimulatory effects induced by 3methylcholanthrene in breast cancer cells and cancer-associated fibroblasts (CAFs). J. Exp. Clin. Cancer Res. 38:335. doi: 10.1186/s13046-019-1337-2

Ciruelos Gil, E. M. (2014). Targeting the PI3K/AKT/mTOR pathway in estrogen receptor-positive breast cancer. Cancer Treat. Rev. 40, 862-871. doi: 10.1016/j. ctrv.2014.03.004

Cordone, I., Masi, S., Summa, V., Carosi, M., Vidiri, A., Fabi, A., et al. (2017). Overexpression of syndecan-1, MUC-1, and putative stem cell markers in breast cancer leptomeningeal metastasis: a cerebrospinal fluid flow cytometry study. Breast Cancer Res. 19:46. doi: 10.1186/s13058-017-0827-4

Cun, X., Chen, J., Li, M., He, X., Tang, X., Guo, R., et al. (2019). Tumor-associated fibroblast-targeted regulation and deep tumor delivery of chemotherapeutic drugs with a multifunctional size-switchable nanoparticle. ACS Appl. Mater. Interf. 11, 39545-39559. doi: 10.1021/acsami.9b13957

Daniel, A. R., and Lange, C. A. (2009). Protein kinases mediate ligand-independent derepression of sumoylated progesterone receptors in breast cancer cells. Proc. Natl. Acad. Sci. U.S.A. 106, 14287-14292. doi: 10.1073/pnas.0905118106

Daubriac, J., Han, S., Grahovac, J., Smith, E., Hosein, A., Buchanan, M., et al. (2018). The crosstalk between breast carcinoma-associated fibroblasts and cancer cells promotes RhoA-dependent invasion via IGF-1 and PAI-1. Oncotarget 9, 10375-10387. doi: 10.18632/oncotarget.23735

De Francesco, E. M., Lappano, R., Santolla, M. F., Marsico, S., Caruso, A., and Maggiolini, M. (2013). HIF-1 $\alpha /$ GPER signaling mediates the expression of VEGF induced by hypoxia in breast cancer associated fibroblasts (CAFs). Breast Cancer Res. 15:R64. doi: 10.1186/bcr3458

De Francesco, E. M., Maggiolini, M., and Musti, A. M. (2018a). Crosstalk between notch, HIF- $1 \alpha$ and GPER in breast cancer EMT. Int. J. Mol. Sci. 19:2011. doi: 10.3390/ijms19072011

De Francesco, E. M., Sotgia, F., and Lisanti, M. P. (2018b). Cancer stem cells (CSCs): metabolic strategies for their identification and eradication. Biochem. J. 475, 1611-1634. doi: 10.1042/BCJ20170164

De Francesco, E. M., Pellegrino, M., Santolla, M. F., Lappano, R., Ricchio, E., Abonante, S., et al. (2014). GPER mediates activation of HIF1 $\alpha /$ VEGF signaling by estrogens. Cancer Res. 74, 4053-4064. doi: 10.1158/0008-5472.CAN-133590

De Francesco, E. M., Sims, A. H., Maggiolini, M., Sotgia, F., Lisanti, M. P., and Clarke, R. B. (2017). GPER mediates the angiocrine actions induced by IGF1 through the HIF-1 $\alpha /$ VEGF pathway in the breast tumor microenvironment. Breast Cancer Res. 19:129. doi: 10.1186/s13058-017-0923-5

De Marco, P., Bartella, V., Vivacqua, A., Lappano, R., Santolla, M. F., Morcavallo, A., et al. (2013). Insulin-like growth factor-I regulates GPER expression and function in cancer cells. Oncogene 32, 678-688. doi: 10.1038/onc.2012.97

De Marco, P., Cirillo, F., Vivacqua, A., Malaguarnera, R., Belfiore, A., and Maggiolini, M. (2015). Novel aspects concerning the functional cross-talk between the Insulin/IGF-I system and estrogen signaling in cancer cells. Front. Endocrinol. 6:30. doi: 10.3389/fendo.2015.00030

De Marco, P., Lappano, R., De Francesco, E. M., Cirillo, F., Pupo, M., Avino, S., et al. (2016). GPER signalling in both cancer-associated fibroblasts and breast cancer cells mediates a feedforward IL1 $\beta / I L 1 R 1$ response. Sci. Rep. 6:24354. doi: 10.1038/srep24354

De Marco, P., Romeo, E., Vivacqua, A., Malaguarnera, R., Abonante, S., Romeo, F., et al. (2014). GPER1 is regulated by insulin in cancer cells and cancer-associated fibroblasts. Endocr. Relat. Cancer 21, 739-753. doi: 10.1530/ERC-14-0245

De Vincenzo, A., Belli, S., Franco, P., Telesca, M., Iaccarino, I., Botti, G., et al. (2019). Paracrine recruitment and activation of fibroblasts by c-Myc expressing breast epithelial cells through the IGFs/IGF-1R axis. Int. J. Cancer 145, 28272839. doi: 10.1002/ijc.32613

DeSantis, C. E., Ma, J., Gaudet, M. M., Newman, L. A., Miller, K. D., Goding Sauer, A., et al. (2019). Breast cancer statistics, 2019. CA Cancer J. Clin. 69, 438-451. doi: $10.3322 /$ caac. 21583

Diep, C. H., Ahrendt, H., and Lange, C. A. (2016). Progesterone induces progesterone receptor gene (PGR) expression via rapid activation of protein kinase pathways required for cooperative estrogen receptor alpha (ER) and progesterone receptor (PR) genomic action at ER/PR target genes. Steroids 114, 48-58. doi: 10.1016/j.steroids.2016.09.004

Dool, C. J., Mashhedi, H., Zakikhani, M., David, S., Zhao, Y., Birman, E., et al. (2011). IGF1/insulin receptor kinase inhibition by BMS-536924 is better tolerated than alloxan-induced hypoinsulinemia and more effective than metformin in the treatment of experimental insulin-responsive breast cancer. Endocr. Relat. Cancer 18, 699-709. doi: 10.1530/ERC-11-0136

Duda, D. G., Duyverman, A. M. M. J., Kohno, M., Snuderl, M., Steller, E. J. A., Fukumura, D., et al. (2010). Malignant cells facilitate lung metastasis by bringing their own soil. Proc. Natl. Acad. Sci. U.S.A. 107, 21677-21682. doi: 10.1073/pnas.1016234107

Dupuy, F., Tabariès, S., Andrzejewski, S., Dong, Z., Blagih, J., Annis, M. G., et al. (2015). PDK1-dependent metabolic reprogramming dictates metastatic potential in breast cancer. Cell Metab. 22, 577-589. doi: 10.1016/j.cmet.2015. 08.007

Echeverria, G. V., and Cooper, T. A. (2014). Muscleblind-like 1 activates insulin receptor exon 11 inclusion by enhancing U2AF65 binding and splicing of the upstream intron. Nucleic Acids Res. 42, 1893-1903. doi: 10.1093/nar/gkt1020

El-Shewy, H. M., and Luttrell, L. M. (2009). Insulin-like growth factor-2/mannose6 phosphate receptors. Vitam. Horm. 80, 667-697. doi: 10.1016/S0083-6729(08) 00624-9

Eyre, R., Alférez, D. G., Santiago-Gómez, A., Spence, K., McConnell, J. C., Hart, C., et al. (2019). Microenvironmental IL1 $\beta$ promotes breast cancer metastatic colonisation in the bone via activation of Wnt signalling. Nat. Commun. 10:5016. doi: 10.1038/s41467-019-12807-0

Fagan, D. H., Uselman, R. R., Sachdev, D., and Yee, D. (2012). Acquired Resistance TO tamoxifen is associated with loss of the Type I insulin-like growth factor receptor: implications for breast cancer treatment. Cancer Res. 72, 3372-3380. doi: 10.1158/0008-5472.CAN-12-0684

Farabaugh, S. M., Boone, D. N., and Lee, A. V. (2015). Role of IGF1R in breast cancer subtypes, stemness, and lineage differentiation. Front. Endocrinol. 6:59. doi: $10.3389 /$ fendo.2015.00059

Fidler, I. J. (2003). The pathogenesis of cancer metastasis: the 'seed and soil' hypothesis revisited. Nat. Rev. Cancer 3, 453-458. doi: 10.1038/nrc1098

Filardo, E. J., Graeber, C. T., Quinn, J. A., Resnick, M. B., Giri, D., DeLellis, R. A., et al. (2006). Distribution of GPR30, a seven membrane-spanning estrogen receptor, in primary breast cancer and its association with clinicopathologic determinants of tumor progression. Clin. Cancer Res. Off. J. Am. Assoc. Cancer Res. 12, 6359-6366. doi: 10.1158/1078-0432.CCR-06-0860

Filardo, E. J., Quinn, J. A., Bland, K. I., and Frackelton, A. R. (2000). Estrogeninduced activation of Erk-1 and Erk-2 requires the $\mathrm{G}$ protein-coupled receptor homolog, GPR30, and occurs via trans-activation of the epidermal growth factor receptor through release of HB-EGF. Mol. Endocrinol. 14, 1649-1660. doi: 10.1210/mend.14.10.0532

Fillmore, C. M., Gupta, P. B., Rudnick, J. A., Caballero, S., Keller, P. J., Lander, E. S., et al. (2010). Estrogen expands breast cancer stem-like cells through paracrine FGF/Tbx3 signaling. Proc. Natl. Acad. Sci. U.S.A. 107, 21737-21742. doi: $10.1073 /$ pnas. 1007863107

Finlay-Schultz, J., and Sartorius, C. A. (2015). Steroid hormones, steroid receptors, and breast cancer stem cells. J. Mamm. Gland. Biol. Neoplasia 20, 39-50. doi: 10.1007/s10911-015-9340-5

Forsare, C., Bendahl, P.-O., Moberg, E., Levin, T. J. C., Jansson, S., Larsson, A.M., et al. (2020). Evolution of estrogen receptor status from primary tumors to metastasis and serially collected circulating tumor cells. Int. J. Mol. Sci. 21:2885. doi: 10.3390/ijms21082885

Frasca, F., Pandini, G., Scalia, P., Sciacca, L., Mineo, R., Costantino, A., et al. (1999). Insulin receptor isoform A, a newly recognized, high-affinity insulinlike growth factor ii receptor in fetal and cancer cells. Mol. Cell Biol. 19, 3278-3288. doi: 10.1128/MCB.19.5.3278

Frasca, F., Pandini, G., Sciacca, L., Pezzino, V., Squatrito, S., Belfiore, A., et al. (2008). The role of insulin receptors and IGF-I receptors in cancer and other diseases. Arch. Physiol. Biochem. 114, 23-37. doi: 10.1080/13813450801969715

Fusco, R., Galgani, M., Procaccini, C., Franco, R., Pirozzi, G., Fucci, L., et al. (2010) Cellular and molecular crosstalk between leptin receptor and estrogen receptor\{alpha\} in breast cancer: molecular basis for a novel therapeutic setting. Endocr. Relat. Cancer 17, 373-382. doi: 10.1677/ERC-09-0340

Gallagher, E. J., and LeRoith, D. (2011). Minireview: IGF. Insulin Cancer Endocrinol. 152, 2546-2551. doi: 10.1210/en.2011-0231

Gao, D., Madi, M., Ding, C., Fok, M., Steele, T., Ford, C., et al. (2014). Interleukin$1 \beta$ mediates macrophage-induced impairment of insulin signaling in human primary adipocytes. Am. J. Physiol. Endocrinol. Metab. 307, E289-E304. doi: 10.1152/ajpendo.00430.2013 
Gao, H., Chakraborty, G., Zhang, Z., Akalay, I., Gadiya, M., Gao, Y., et al. (2016). Multi-organ site metastatic reactivation mediated by non-canonical discoidin domain receptor 1 signaling. Cell 166, 47-62. doi: 10.1016/j.cell.2016.06.009

Ghosh, S., Ashcraft, K., Jahid, M. J., April, C., Ghajar, C. M., Ruan, J., et al. (2013). Regulation of adipose oestrogen output by mechanical stress. Nat. Commun. 4:1821. doi: $10.1038 /$ ncomms 2794

Giordano, C., Chemi, F., Panza, S., Barone, I., Bonofiglio, D., Lanzino, M., et al. (2016). Leptin as a mediator of tumor-stromal interactions promotes breast cancer stem cell activity. Oncotarget 7, 1262-1275. doi: 10.18632/oncotarget. 6014

Giovannelli, P., Di Donato, M., Giraldi, T., Migliaccio, A., Castoria, G., and Auricchio, F. (2012). Targeting rapid action of sex-steroid receptors in breast and prostate cancers. Front. Biosci. 4, 453-461. doi: 10.2741/390

Giretti, M. S., Fu, X.-D., De Rosa, G., Sarotto, I., Baldacci, C., Garibaldi, S., et al. (2008). Extra-nuclear signalling of estrogen receptor to breast cancer cytoskeletal remodelling, migration and invasion. PLoS One 3:e2238. doi: 10. 1371/journal.pone.0002238

Girnita, A., Girnita, L., del Prete, F., Bartolazzi, A., Larsson, O., and Axelson, M. (2004). Cyclolignans as inhibitors of the insulin-like growth factor-1 receptor and malignant cell growth. Cancer Res. 64, 236-242. doi: 10.1158/0008-5472. CAN-03-2522

Goswami, S., Sahai, E., Wyckoff, J. B., Cammer, M., Cox, D., Pixley, F. J., et al. (2005). Macrophages promote the invasion of breast carcinoma cells via a colony-stimulating factor-1/epidermal growth factor paracrine loop. Cancer Res. 65, 5278-5283. doi: 10.1158/0008-5472.CAN-04-1853

Goto, W., Kashiwagi, S., Asano, Y., Takada, K., Takahashi, K., Hatano, T., et al. (2017). Circulating tumor cell clusters-associated gene plakoglobin is a significant prognostic predictor in patients with breast cancer. Biomark. Res. 5:19. doi: 10.1186/s40364-017-0099-2

Gui, Y., Aguilar-Mahecha, A., Krzemien, U., Hosein, A., Buchanan, M., Lafleur, J., et al. (2019). Metastatic breast carcinoma-associated fibroblasts have enhanced protumorigenic properties related to increased IGF2 expression. Clin. Cancer Res. 25, 7229-7242. doi: 10.1158/1078-0432.CCR-19-1268

Guo, S., and Deng, C.-X. (2018). Effect of stromal cells in tumor microenvironment on metastasis initiation. Int. J. Biol. Sci. 14, 2083-2093. doi: 10.7150/ijbs.25720

Guvakova, M. A., and Surmacz, E. (1997). Tamoxifen interferes with the insulinlike growth factor I receptor (IGF-IR) signaling pathway in breast cancer cells. Cancer Res. 57, 2606-2610.

Gyamfi, J., Lee, Y.-H., Eom, M., and Choi, J. (2018). Interleukin-6/STAT3 signalling regulates adipocyte induced epithelial-mesenchymal transition in breast cancer cells. Sci. Rep. 8:8859. doi: 10.1038/s41598-018-27184-9

Hanahan, D., and Coussens, L. M. (2012). Accessories to the crime: functions of cells recruited to the tumor microenvironment. Cancer Cell. 21, 309-322. doi: 10.1016/j.ccr.2012.02.022

Hao, N.-B., Lü, M.-H., Fan, Y.-H., Cao, Y.-L., Zhang, Z.-R., and Yang, S.-M. (2012). Macrophages in tumor microenvironments and the progression of tumors. Clin. Dev. Immunol. 2012:948098. doi: 10.1155/2012/948098

Harding, J. L., Andes, L. J., Gregg, E. W., Cheng, Y. J., Weir, H. K., Bullard, K. M., et al. (2020). Trends in cancer mortality among people with vs without diabetes in the USA, 1988-2015. Diabetologia 63, 75-84. doi: 10.1007/s00125-01904991-x

Hilton, H. N., Graham, J. D., Kantimm, S., Santucci, N., Cloosterman, D., Huschtscha, L. I., et al. (2012). Progesterone and estrogen receptors segregate into different cell subpopulations in the normal human breast. Mol. Cell Endocrinol. 361, 191-201. doi: 10.1016/j.mce.2012.04.010

Hiraga, T., Myoui, A., Hashimoto, N., Sasaki, A., Hata, K., Morita, Y., et al. (2012). Bone-derived IGF mediates crosstalk between bone and breast cancer cells in bony metastases. Cancer Res. 72, 4238-4249. doi: 10.1158/0008-5472.CAN-113061

Ho, K.-H., Chen, P.-H., Hsi, E., Shih, C.-M., Chang, W.-C., Cheng, C.-H., et al. (2017). Identification of IGF-1-enhanced cytokine expressions targeted by miR181d in glioblastomas via an integrative miRNA/mRNA regulatory network analysis. Sci. Rep. 7:732. doi: 10.1038/s41598-017-00826-0

Hoshino, A., Costa-Silva, B., Shen, T.-L., Rodrigues, G., Hashimoto, A., Tesic Mark, M., et al. (2015). Tumour exosome integrins determine organotropic metastasis. Nature 527, 329-335. doi: 10.1038/nature 15756
Hosseini, H., Obradović, M. M. S., Hoffmann, M., Harper, K. L., Sosa, M. S., Werner-Klein, M., et al. (2016). Early dissemination seeds metastasis in breast cancer. Nature 540, 552-558. doi: 10.1038/nature20785

Howell, A., Clarke, R. B., Evans, G., Bundred, N., Cuzick, J., Santen, R., et al. (2007). Estrogen deprivation for breast cancer prevention. Recent Results Cancer Res. 174, 151-167. doi: 10.1007/978-3-540-37696-5_13

Hsieh, J. Y., Smith, T. D., Meli, V. S., Tran, T. N., Botvinick, E. L., and Liu, W. F. (2017). Differential regulation of macrophage inflammatory activation by fibrin and fibrinogen. Acta Biomater. 47, 14-24. doi: 10.1016/j.actbio.2016.09.024

Huang, J., Morehouse, C., Streicher, K., Higgs, B. W., Gao, J., Czapiga, M., et al. (2011). Altered expression of insulin receptor isoforms in breast cancer. PLoS One 6:e26177. doi: 10.1371/journal.pone.0026177

Ignatov, A., Ignatov, T., Weissenborn, C., Eggemann, H., Bischoff, J., Semczuk, A., et al. (2011). G-protein-coupled estrogen receptor GPR30 and tamoxifen resistance in breast cancer. Breast Cancer Res. Treat. 128, 457-466. doi: 10. 1007/s10549-011-1584-1

Iguchi, H., Nishina, T., Nogami, N., Kozuki, T., Yamagiwa, Y., and Yagawa, K. (2015). Phase I dose-escalation study evaluating safety, tolerability and pharmacokinetics of MEDI-573, a dual IGF-I/II neutralizing antibody, in Japanese patients with advanced solid tumours. Invest. New Drugs 33, 194-200. doi: 10.1007/s10637-014-0170-x

Ireland, L., Santos, A., Campbell, F., Figueiredo, C., Hammond, D., Ellies, L. G., et al. (2018). Blockade of insulin-like growth factors increases efficacy of paclitaxel in metastatic breast cancer. Oncogene 37, 2022-2036. doi: 10.1038/ s41388-017-0115-x

Iyengar, N. M., Hudis, C. A., and Dannenberg, A. J. (2013). Obesity and inflammation: new insights into breast cancer development and progression. Am. Soc. Clin. Oncol. Educ. Book 33, 46-51. doi: 10.1200/EdBook_AM.2013. 33.46

Jallow, F., O’Leary, K. A., Rugowski, D. E., Guerrero, J. F., Ponik, S. M., and Schuler, L. A. (2019). Dynamic interactions between the extracellular matrix and estrogen activity in progression of ER+ breast cancer. Oncogene 38, 69136925. doi: 10.1038/s41388-019-0941-0

Jia, S., Liu, Z., Zhang, S., Liu, P., Zhang, L., Lee, S. H., et al. (2008). Essential roles of PI(3)K-p110beta in cell growth, metabolism and tumorigenesis. Nature 454, 776-779. doi: 10.1038/nature07091

Kahlert, S., Nuedling, S., van Eickels, M., Vetter, H., Meyer, R., and Grohe, C. (2000). Estrogen receptor alpha rapidly activates the IGF-1 receptor pathway. J. Biol. Chem. 275, 18447-18453. doi: 10.1074/jbc.M910345199

Kalluri, R. (2016). The biology and function of fibroblasts in cancer. Nat. Rev. Cancer 16, 582-598. doi: 10.1038/nrc.2016.73

Kamat, P., Schweizer, R., Kaenel, P., Salemi, S., Calcagni, M., Giovanoli, P., et al. (2015). Human adipose-derived mesenchymal stromal cells may promote breast cancer progression and metastatic spread. Plast. Reconstr. Surg. 136, 76-84. doi: 10.1097/PRS.0000000000001321

Kasprzak, A., Kwasniewski, W., Adamek, A., and Gozdzicka-Jozefiak, A. (2017). Insulin-like growth factor (IGF) axis in cancerogenesis. Mutat. Res. Rev. Mutat. Res. 772, 78-104. doi: 10.1016/j.mrrev.2016.08.007

Katsura, A., Tamura, Y., Hokari, S., Harada, M., Morikawa, M., Sakurai, T., et al. (2017). ZEB1-regulated inflammatory phenotype in breast cancer cells. Mol. Oncol. 11, 1241-1262. doi: 10.1002/1878-0261.12098

Katzenellenbogen, B. S., and Frasor, J. (2004). Therapeutic targeting in the estrogen receptor hormonal pathway. Semin. Oncol. 31(1 Suppl. 3), 28-38. doi: 10.1053/ j.seminoncol.2004.01.004

Kessenbrock, K., Plaks, V., and Werb, Z. (2010). Matrix metalloproteinases: regulators of the tumor microenvironment. Cell 141, 52-67. doi: 10.1016/j.cell. 2010.03.015

Kim, H.-J., Litzenburger, B. C., Cui, X., Delgado, D. A., Grabiner, B. C., Lin, X., et al. (2007). Constitutively active Type I insulin-like growth factor receptor causes transformation and xenograft growth of immortalized mammary epithelial cells and is accompanied by an epithelial-to-mesenchymal transition mediated by NF-кB and snail. Mol. Cell Biol. 27, 3165-3175. doi: 10.1128/MCB.01315-06

Knutson, T. P., Truong, T. H., Ma, S., Brady, N. J., Sullivan, M. E., Raj, G., et al. (2017). Posttranslationally modified progesterone receptors direct ligand-specific expression of breast cancer stem cell-associated gene programs. J. Hematol. Oncol. 10:89. doi: 10.1186/s13045-017-0462-7 
Kumar, R., Zakharov, M. N., Khan, S. H., Miki, R., Jang, H., Toraldo, G., et al. (2011). The dynamic structure of the estrogen receptor. J. Amino Acids 2011:812540. doi: 10.4061/2011/812540

Lapeire, L., Hendrix, A., Lambein, K., Van Bockstal, M., Braems, G., Van Den Broecke, R., et al. (2014). Cancer-associated adipose tissue promotes breast cancer progression by paracrine oncostatin M and Jak/STAT3 signaling. Cancer Res. 74, 6806-6819. doi: 10.1158/0008-5472.CAN-14-0160

Lappano, R., De Marco, P., De Francesco, E. M., Chimento, A., Pezzi, V., and Maggiolini, M. (2013). Cross-talk between GPER and growth factor signaling. J. Steroid. Biochem. Mol. Biol. 137, 50-56. doi: 10.1016/j.jsbmb.2013. 03.005

Lappano, R., and Maggiolini, M. (2018). GPER is involved in the functional liaison between breast tumor cells and cancer-associated fibroblasts (CAFs). J. Steroid. Biochem. Mol. Biol. 176, 49-56. doi: 10.1016/j.jsbmb.2017.02.019

Lappano, R., Pisano, A., and Maggiolini, M. (2014). GPER function in breast cancer: an overview. Front. Endocrinol. 5:66. doi: 10.3389/fendo.2014.00066

Lappano, R., Rigiracciolo, D. C., Belfiore, A., Maggiolini, M., and De Francesco, E. M. (2020a). Cancer associated fibroblasts: role in breast cancer and potential as therapeutic targets. Expert. Opin Ther. Targets 24, 559-572. doi: 10.1080/ 14728222.2020.1751819

Lappano, R., Talia, M., Cirillo, F., Rigiracciolo, D. C., Scordamaglia, D., Guzzi, R., et al. (2020b). The IL1 $\beta$-IL1R signaling is involved in the stimulatory effects triggered by hypoxia in breast cancer cells and cancer-associated fibroblasts (CAFs). J. Exp. Clin. Cancer Res. 39:153. doi: 10.1186/s13046-020-01667-y

Law, J. H., Habibi, G., Hu, K., Masoudi, H., Wang, M. Y. C., Stratford, A. L., et al. (2008). Phosphorylated insulin-like growth factor-i/insulin receptor is present in all breast cancer subtypes and is related to poor survival. Cancer Res. 68, 10238-10246. doi: 10.1158/0008-5472.CAN-08-2755

Lee, J.-S., Kang, J.-H., Boo, H.-J., Hwang, S.-J., Hong, S., Lee, S.-C., et al. (2006). STAT3-mediated IGF-2 secretion in the tumour microenvironment elicits innate resistance to anti-IGF-1R antibody. Nat. Commun. 6:8499. doi: 10.1038/ ncomms 9499

Lee, S.-C., Min, H.-Y., Jung, H. J., Park, K. H., Hyun, S. Y., Cho, J., et al. (2016). Essential role of insulin-like growth factor 2 in resistance to histone deacetylase inhibitors. Oncogene 35, 5515-5526. doi: 10.1038/onc.2016.92

Lee, Y., Jung, W. H., and Koo, J. S. (2015). Adipocytes can induce epithelialmesenchymal transition in breast cancer cells. Breast Cancer Res. Treat. 153, 323-335. doi: 10.1007/s10549-015-3550-9

Levin, E. R. (2003). Bidirectional signaling between the estrogen receptor and the epidermal growth factor receptor. Mol. Endocrinol. 17, 309-317. doi: 10.1210/ me.2002-0368

Levin, E. R. (2009). Plasma membrane estrogen receptors. Trends Endocrinol. Metab. TEM 20, 477-482. doi: 10.1016/j.tem.2009.06.009

Levin, E. R., and Pietras, R. J. (2008). Estrogen receptors outside the nucleus in breast cancer. Breast Cancer Res. Treat. 108, 351-361. doi: 10.1007/s10549-0079618-4

Lewitt, M. S., Dent, M. S., and Hall, K. (2014). The insulin-like growth factor system in obesity, insulin resistance and Type 2 diabetes mellitus. J. Clin. Med. 3, 1561-1574. doi: 10.3390/jcm3041561

Li, D., Ji, H., Niu, X., Yin, L., Wang, Y., Gu, Y., et al. (2020). Tumor-associated macrophages secrete $\mathrm{CC}$-chemokine ligand 2 and induce tamoxifen resistance by activating PI3K/Akt/mTOR in breast cancer. Cancer Sci. 111, 47-58. doi: $10.1111 /$ cas. 14230

Litzenburger, B. C., Creighton, C. J., Tsimelzon, A., Chan, B. T., Hilsenbeck, S. G., Wang, T., et al. (2011). High IGF-IR activity in triple-negative breast cancer cell lines and tumorgrafts correlates with sensitivity to anti-IGF-IR therapy. Clin. Cancer Res. Off. J. Am. Assoc. Cancer Res. 17, 2314-2327. doi: 10.1158/10780432.CCR-10-1903

Litzenburger, B. C., Kim, H.-J., Kuiatse, I., Carboni, J. M., Attar, R. M., Gottardis, M. M., et al. (2009). BMS-536924 reverses IGF-IR-induced transformation of mammary epithelial cells and causes growth inhibition and polarization of MCF7 cells. Clin. Cancer Res. Off. J. Am. Assoc. Cancer Res. 15, 226-237. doi: 10.1158/1078-0432.CCR-08-0801

Liu, E., Samad, F., and Mueller, B. M. (2013). Local adipocytes enable estrogendependent breast cancer growth: role of leptin and aromatase. Adipocyte 2, 165-169. doi: 10.4161/adip. 23645

Liu, H., Wang, J., Zhang, M., Xuan, Q., Wang, Z., Lian, X., et al. (2017). Jagged1 promotes aromatase inhibitor resistance by modulating tumor-associated macrophage differentiation in breast cancer patients. Breast Cancer Res. Treat. 166, 95-107. doi: 10.1007/s10549-017-4394-2

Liu, Q., Li, J., Zheng, X., Jin, F., and Dong, H. (2009). Expression of CD133, PAX2, ESA, and GPR30 in invasive ductal breast carcinomas. Chin. Med. J. 122, 2763-2769.

Liu, Y.-Q., Tian, J., Qian, K., Zhao, X.-B., Morris-Natschke, S. L., Yang, L., et al. (2015). Recent progress on C-4-modified podophyllotoxin analogs as potent antitumor agents. Med. Res. Rev. 35, 1-62. doi: 10.1002/med.21319

Luo, H., Yang, G., Yu, T., Luo, S., Wu, C., Sun, Y., et al. (2014). GPER-mediated proliferation and estradiol production in breast cancer-associated fibroblasts. Endocr. Relat. Cancer 21, 355-369. doi: 10.1530/ERC-13-0237

Ma, C. X., Reinert, T., Chmielewska, I., and Ellis, M. J. (2015). Mechanisms of aromatase inhibitor resistance. Nat. Rev. Cancer 15, 261-275. doi: 10.1038/ nrc3920

Ma, R., Feng, Y., Lin, S., Chen, J., Lin, H., Liang, X., et al. (2015). Mechanisms involved in breast cancer liver metastasis. J. Transl. Med. 13:64. doi: 10.1186/ s12967-015-0425-0

Madeo, A., and Maggiolini, M. (2010). Nuclear alternate estrogen receptor GPR30 mediates 17beta-estradiol-induced gene expression and migration in breast cancer-associated fibroblasts. Cancer Res. 70, 6036-6046. doi: 10.1158/00085472.CAN-10-0408

Mak, M. P., Tong, P., Diao, L., Cardnell, R. J., Gibbons, D. L., William, W. N., et al. (2016). A patient-derived, pan-cancer EMT Signature identifies global molecular alterations and immune target enrichment following epithelial-tomesenchymal transition. Clin. Cancer Res. 22, 609-620. doi: 10.1158/10780432.CCR-15-0876

Malaguarnera, R., and Belfiore, A. (2014). The emerging role of insulin and insulinlike growth factor signaling in cancer stem cells. Front. Endocrinol. 5:10. doi: 10.3389/fendo.2014.00010

Malaguarnera, R., Frasca, F., Garozzo, A., Gianì, F., Pandini, G., Vella, V., et al. (2011). Insulin receptor Isoforms and insulin-like growth factor receptor in human follicular cell precursors from papillary thyroid cancer and normal thyroid. J. Clin. Endocrinol. Metab. 96, 766-774. doi: 10.1210/jc.2010-1255

Malaguarnera, R., Morcavallo, A., and Belfiore, A. (2012a). The insulin and IGFI pathway in endocrine glands carcinogenesis. J. Oncol. 2012:635614. doi: $10.1155 / 2012 / 635614$

Malaguarnera, R., Sacco, A., Voci, C., Pandini, G., Vigneri, R., and Belfiore, A. (2012b). proinsulin binds with high affinity the insulin receptor Isoform A and predominantly activates the mitogenic pathway. Endocrinology 153, 2152-2163. doi: 10.1210/en.2011-1843

Mani, S. A., Guo, W., Liao, M.-J., Eaton, E. N., Ayyanan, A., Zhou, A. Y., et al. (2008). The epithelial-mesenchymal transition generates cells with properties of stem cells. Cell 133, 704-715. doi: 10.1016/j.cell.2008.03.027

Manzella, L., Massimino, M., Stella, S., Tirrò, E., Pennisi, M. S., Martorana, F., et al. (2019). Activation of the IGF axis in thyroid cancer: implications for tumorigenesis and treatment. Int. J. Mol. Sci. 20:3258. doi: 10.3390/ ijms 20133258

Marjon, N. A., Hu, C., Hathaway, H. J., and Prossnitz, E. R. (2014). G proteincoupled estrogen receptor regulates mammary tumorigenesis and metastasis. Mol. Cancer Res. 12, 1644-1654. doi: 10.1158/1541-7786.MCR-14-0128-T

Martin, S. G., Lebot, M. N., Sukkarn, B., Ball, G., Green, A. R., Rakha, E. A., et al. (2018). Low expression of $G$ protein-coupled oestrogen receptor 1 (GPER) is associated with adverse survival of breast cancer patients. Oncotarget 9, 25946-25956. doi: 10.18632/oncotarget.25408

Matà, R., Palladino, C., Nicolosi, M. L., Presti, A. R. L., Malaguarnera, R., Ragusa, M., et al. (2016). IGF-I induces upregulation of DDR1 collagen receptor in breast cancer cells by suppressing MIR-199a-5p through the PI3K/AKT pathway. Oncotarget 7, 7683-7700. doi: 10.18632/oncotarget.6524

McCarthy, J. B., El-Ashry, D., and Turley, E. A. (2018). Hyaluronan, cancerassociated fibroblasts and the tumor microenvironment in malignant progression. Front. Cell Dev. Biol. 6:48. doi: 10.3389/fcell.2018.00048

McDonnell, D. P., and Norris, J. D. (2002). Connections and regulation of the human estrogen receptor. Science 296, 1642-1644. doi: 10.1126/science. 1071884

Migliaccio, A., Di Domenico, M., Castoria, G., de Falco, A., Bontempo, P., Nola, E., et al. (1996). Tyrosine kinase/p21ras/MAP-kinase pathway activation by estradiol-receptor complex in MCF-7 cells. EMBO J. 15, 1292-1300. doi: 10. 1002/j.1460-2075.1996.tb00471.x 
Mirdamadi, Y., Thielitz, A., Wiede, A., Goihl, A., Papakonstantinou, E., Hartig, R., et al. (2015). Insulin and insulin-like growth factor-1 can modulate the phosphoinositide-3-kinase/Akt/FoxO1 pathway in SZ95 sebocytes in vitro. Mol. Cell Endocrinol. 415, 32-44. doi: 10.1016/j.mce.2015.08.001

Mohammed, H., Russell, I. A., Stark, R., Rueda, O. M., Hickey, T. E., Tarulli, G. A., et al. (2015). Progesterone receptor modulates $\mathrm{ER} \alpha$ action in breast cancer. Nature 523, 313-317. doi: 10.1038/nature14583

Morcavallo, A., Buraschi, S., Xu, S.-Q., Belfiore, A., Schaefer, L., Iozzo, R. V., et al. (2014). Decorin differentially modulates the activity of insulin receptor isoform A ligands. Matrix Biol. 35, 82-90. doi: 10.1016/j.matbio.2013.12.010

Motallebnezhad, M., Aghebati-Maleki, L., Jadidi-Niaragh, F., Nickho, H., SamadiKafil, H., Shamsasenjan, K., et al. (2016). The insulin-like growth factor-I receptor (IGF-IR) in breast cancer: biology and treatment strategies. Tumour Biol. J. Int. Soc. Oncodevelopment. Biol. Med. 37, 11711-11721. doi: 10.1007/ s13277-016-5176-x

Mutebi, M., Anderson, B. O., Duggan, C., Adebamowo, C., Agarwal, G., Ali, Z., et al. (2020). Breast cancer treatment: a phased approach to implementation. Cancer 126(Suppl. 10), 2365-2378. doi: 10.1002/cncr.32910

Neman, J., Termini, J., Wilczynski, S., Vaidehi, N., Choy, C., Kowolik, C. M., et al. (2014). Human breast cancer metastases to the brain display GABAergic properties in the neural niche. Proc. Natl. Acad. Sci. U.S.A. 111, 984-989. doi: 10.1073/pnas.1322098111

Nguyen, D. X., and Massagué, J. (2007). Genetic determinants of cancer metastasis. Nat. Rev. Genet. 8, 341-352. doi: 10.1038/nrg2101

Noman, M. Z., Janji, B., Abdou, A., Hasmim, M., Terry, S., Tan, T. Z., et al. (2017). The immune checkpoint ligand PD-L1 is upregulated in EMT-activated human breast cancer cells by a mechanism involving ZEB-1 and miR-200. Oncoimmunology 6:e1263412. doi: 10.1080/2162402X.2016.1263412

Obeid, E., Nanda, R., Fu, Y.-X., and Olopade, O. I. (2013). The role of tumorassociated macrophages in breast cancer progression (review). Int. J. Oncol. 43, 5-12. doi: 10.3892/ijo.2013.1938

Oh, K., Lee, O.-Y., Park, Y., Seo, M. W., and Lee, D.-S. (2016). IL-1 $\beta$ induces IL6 production and increases invasiveness and estrogen-independent growth in a TG2-dependent manner in human breast cancer cells. BMC Cancer 16:724 doi: 10.1186/s12885-016-2746-7

Osborne, C. K., and Schiff, R. (2011). Mechanisms of endocrine resistance in breast cancer. Annu. Rev. Med. 62, 233-247. doi: 10.1146/annurev-med-070909182917

O'Sullivan, C., Lewis, C. E., Harris, A. L., and McGee, J. O. (1993). Secretion of epidermal growth factor by macrophages associated with breast carcinoma. Lancet Lond. Engl. 342, 148-149. doi: 10.1016/0140-6736(93)91348-P

Ouyang, L., Chang, W., Fang, B., Qin, J., Qu, X., and Cheng, F. (2016). Estrogeninduced SDF-1 $\alpha$ production promotes the progression of ER-negative breast cancer via the accumulation of MDSCs in the tumor microenvironment. Sci. Rep. 6:39541. doi: 10.1038/srep39541

Pandey, D. P., Lappano, R., Albanito, L., Madeo, A., Maggiolini, M., and Picard, D. (2009). Estrogenic GPR30 signalling induces proliferation and migration of breast cancer cells through CTGF. EMBO J. 28, 523-532. doi: 10.1038/emboj. 2008.304

Park, Y.-M. M., White, A. J., Nichols, H. B., O’Brien, K. M., Weinberg, C. R., and Sandler, D. P. (2017). The association between metabolic health, obesity phenotype and the risk of breast cancer. Int. J. Cancer 140, 2657-2666. doi: 10.1002/ijc.30684

Pasanisi, P., Venturelli, E., Morelli, D., Fontana, L., Secreto, G., and Berrino, F. (2008). Serum insulin-like growth factor-I and platelet-derived growth factor as biomarkers of breast cancer prognosis. Cancer Epidemiol. Biomark. Prev. 17, 1719-1722. doi: 10.1158/1055-9965.EPI-07-0654

Peake, B. F., Eze, S. M., Yang, L., Castellino, R. C., and Nahta, R. (2017). Growth differentiation factor 15 mediates epithelial mesenchymal transition and invasion of breast cancers through IGF-1R-FoxM1 signaling. Oncotarget 8, 94393-94406. doi: 10.18632/oncotarget.21765

Philippou, A., Christopoulos, P. F., and Koutsilieris, D. M. (2017). Clinical studies in humans targeting the various components of the IGF system show lack of efficacy in the treatment of cancer. Mutat. Res. Rev. Mutat. Res. 772, 105-122. doi: 10.1016/j.mrrev.2016.09.005

Pirola, L., Bonnafous, S., Johnston, A. M., Chaussade, C., Portis, F., and Van Obberghen, E. (2003). Phosphoinositide 3-kinase-mediated reduction of insulin receptor substrate-1/2 protein expression via different mechanisms contributes to the insulin-induced desensitization of its signaling pathways in L6 muscle cells. J. Biol. Chem. 278, 15641-15651. doi: 10.1074/jbc.M208984200

Pisano, A., Santolla, M. F., De Francesco, E. M., De Marco, P., Rigiracciolo, D. C., Perri, M. G., et al. (2017). GPER, IGF-IR, and EGFR transduction signaling are involved in stimulatory effects of zinc in breast cancer cells and cancerassociated fibroblasts. Mol. Carcinog. 56, 580-593. doi: 10.1002/mc.22518

Polyak, K., and Weinberg, R. A. (2009). Transitions between epithelial and mesenchymal states: acquisition of malignant and stem cell traits. Nat. Rev. Cancer. 9, 265-273. doi: 10.1038/nrc2620

Prossnitz, E. R., and Arterburn, J. B. (2015). International union of basic and clinical pharmacology. XCVII. G protein-coupled estrogen receptor and its pharmacologic modulators. Pharmacol. Rev. 67, 505-540. doi: 10.1124/pr.114. 009712

Pupo, M., Bodmer, A., Berto, M., Maggiolini, M., Dietrich, P.-Y., and Picard, D. (2017). A genetic polymorphism repurposes the G-protein coupled and membrane-associated estrogen receptor GPER to a transcription factor-like molecule promoting paracrine signaling between stroma and breast carcinoma cells. Oncotarget 8, 46728-46744. doi: 10.18632/oncotarget.18156

Pupo, M., Pisano, A., Abonante, S., Maggiolini, M., and Musti, A. M. (2014). GPER activates Notch signaling in breast cancer cells and cancer-associated fibroblasts (CAFs). Int. J. Biochem. Cell Biol. 46, 56-67. doi: 10.1016/j.biocel.2013.11.011

Pupo, M., Vivacqua, A., Perrotta, I., Pisano, A., Aquila, S., Abonante, S., et al. (2013). The nuclear localization signal is required for nuclear GPER translocation and function in breast Cancer-Associated Fibroblasts (CAFs). Mol. Cell Endocrinol. 376, 23-32. doi: 10.1016/j.mce.2013.05.023

Qiu, M., Olsen, A., Faivre, E., Horwitz, K. B., and Lange, C. A. (2003). Mitogenactivated protein kinase regulates nuclear association of human progesterone receptors. Mol. Endocrinol. 17, 628-642. doi: 10.1210/me.2002-0378

Qu, X., Wu, Z., Dong, W., Zhang, T., Wang, L., Pang, Z., et al. (2017). Update of IGF-1 receptor inhibitor (ganitumab, dalotuzumab, cixutumumab, teprotumumab and figitumumab) effects on cancer therapy. Oncotarget 8, 29501-29518. doi: 10.18632/oncotarget.15704

Ramaswamy, S., Ross, K. N., Lander, E. S., and Golub, T. R. (2003). A molecular signature of metastasis in primary solid tumors. Nat. Genet. 33, 49-54. doi: $10.1038 /$ ng 1060

Razandi, M., Oh, P., Pedram, A., Schnitzer, J., and Levin, E. R. (2002). ERs associate with and regulate the production of caveolin: implications for signaling and cellular actions. Mol. Endocrinol. 16, 100-115. doi: 10.1210/mend.16.1.0757

Razandi, M., Pedram, A., Greene, G. L., and Levin, E. R. (1999). Cell membrane and nuclear estrogen receptors (ERs) originate from a single transcript: studies of ERalpha and ERbeta expressed in Chinese hamster ovary cells. Mol. Endocrinol. 3, 307-319. doi: 10.1210/me.13.2.307

Razandi, M., Pedram, A., Park, S. T., and Levin, E. R. (2003). Proximal events in signaling by plasma membrane estrogen receptors. J. Biol. Chem. 278, 2701-2712. doi: 10.1074/jbc.M205692200

Ren, J., Guo, H., Wu, H., Tian, T., Dong, D., Zhang, Y., et al. (2015). GPER in CAFs regulates hypoxia-driven breast cancer invasion in a CTGF-dependent manner. Oncol. Rep. 33, 1929-1937. doi: 10.3892/or.2015.3779

Revankar, C. M., Cimino, D. F., Sklar, L. A., Arterburn, J. B., and Prossnitz, E. R. (2005). A transmembrane intracellular estrogen receptor mediates rapid cell signaling. Science 307, 1625-1630. doi: 10.1126/science.1106943

Robertson, J. F., Ferrero, J.-M., Bourgeois, H., Kennecke, H., de Boer, R. H. Jacot, W., et al. (2013). Ganitumab with either exemestane or fulvestrant for postmenopausal women with advanced, hormone-receptor-positive breast cancer: a randomised, controlled, double-blind, phase 2 trial. Lancet Oncol. 14, 228-235. doi: 10.1016/S1470-2045(13)70026-3

Rondón-Lagos, M., Villegas, V. E., Rangel, N., Sánchez, M. C., and Zaphiropoulos, P. G. (2016). Tamoxifen resistance: emerging molecular targets. Int. J. Mol. Sci. 17:1357. doi: 10.3390/ijms 17081357

Rothenberger, N. J., Somasundaram, A., and Stabile, L. P. (2018). The role of the estrogen pathway in the tumor microenvironment. Int. J. Mol. Sci. 19:611. doi: 10.3390/ijms19020611

Ruh, M. F., Bi, Y., D’Alonzo, R., and Bellone, C. J. (1998). Effect of estrogens on IL-1beta promoter activity. J. Steroid. Biochem. Mol. Biol. 66, 203-210. doi: 10.1016/S0960-0760(98)00042-9

Ryan, P., Neven, P., Blackwell, K., Dirix, L., Barrios, C., Miller, W., et al. (2011). P117-01: figitumumab plus exemestane versus exemestane as first-line treatment of postmenopausal hormone receptor-positive advanced breast cancer: a 
randomized, open-label phase II trial. Cancer Res. 71(24 Suppl.):Abstract nr P1-17-01. doi: 10.1158/0008-5472.SABCS11-P1-17-01

Sabbah, M., Courilleau, D., Mester, J., and Redeuilh, G. (1999). Estrogen induction of the cyclin D1 promoter: involvement of a cAMP response-like element. Proc. Natl. Acad. Sci. U.S.A. 96, 11217-11222. doi: 10.1073/pnas.96.20.11217

Sabol, R. A., Beighley, A., Giacomelli, P., Wise, R. M., Harrison, M. A. A., O'Donnnell, B. A., et al. (2019). Obesity-altered adipose stem cells promote ER+ Breast cancer metastasis through estrogen independent pathways. Int. J. Mol. Sci. 20:1419. doi: 10.3390/ijms20061419

Sakurai, M., Miki, Y., Takagi, K., Suzuki, T., Ishida, T., Ohuchi, N., et al. (2017). Interaction with adipocyte stromal cells induces breast cancer malignancy via S100A7 upregulation in breast cancer microenvironment. Breast Cancer Res. 19:70. doi: 10.1186/s13058-017-0863-0

Sanchez-Infantes, D., White, U. A., Elks, C. M., Morrison, R. F., Gimble, J. M., Considine, R. V., et al. (2014). Oncostatin M is produced in adipose tissue and is regulated in conditions of obesity and Type 2 diabetes. J. Clin. Endocrinol. Metab. 99, E217-E225. doi: 10.1210/jc.2013-3555

Sangai, T., Fujimoto, H., Miyamoto, S., Maeda, H., Nakamura, M., Ishii, G., et al. (2008). Roles of osteoclasts and bone-derived IGFs in the survival and growth of human breast cancer cells in human adult bone implanted into nonobese diabetic/severe combined immunodeficient mice. Clin. Exp. Metast. 25, 401-410. doi: 10.1007/s10585-008-9144-8

Santolla, M. F., Vivacqua, A., Lappano, R., Rigiracciolo, D. C., Cirillo, F., Galli, G. R., et al. (2019). GPER mediates a feedforward FGF2/FGFR1 paracrine activation coupling CAFs to cancer cells toward breast tumor progression. Cells 8:233. doi: $10.3390 /$ cells 8030223

Saxena, N. K., Taliaferro-Smith, L., Knight, B. B., Merlin, D., Anania, F. A., O’Regan, R. M., et al. (2008). Bidirectional crosstalk between leptin and insulinlike growth factor-I signaling promotes invasion and migration of breast cancer cells via transactivation of epidermal growth factor receptor. Cancer Res. 68 , 9712-9722. doi: 10.1158/0008-5472.CAN-08- 1952

Schito, L., and Semenza, G. L. (2016). Hypoxia-inducible factors: master regulators of cancer progression. Trends Cancer 2, 758-770. doi: 10.1016/j.trecan.2016.10. 016

Schrauder, M. G., Fasching, P. A., Häberle, L., Lux, M. P., Rauh, C., Hein, A., et al. (2011). Diabetes and prognosis in a breast cancer cohort. J. Cancer Res. Clin. Oncol. 137, 975-983. doi: 10.1007/s00432-010-0960-2

Semenza, G. L. (2012). Molecular mechanisms mediating metastasis of hypoxic breast cancer cells. Trends Mol. Med. 18, 534-543. doi: 10.1016/j.molmed.2012. 08.001

Senkus, E., Kyriakides, S., Penault-Llorca, F., Poortmans, P., Thompson, A., Zackrisson, S., et al. (2013). Primary breast cancer: ESMO clinical practice guidelines for diagnosis, treatment and follow-up. Ann. Oncol. Off. J. Eur. Soc. Med. Oncol. 24(Suppl. 6), vi7-vi23. doi: 10.1093/annonc/mdt284

Sisci, D., Morelli, C., Cascio, S., Lanzino, M., Garofalo, C., Reiss, K., et al. (2007). The estrogen receptor alpha:insulin receptor substrate 1 complex in breast cancer: structure-function relationships. Ann. Oncol. Off. J. Eur. Soc. Med. Oncol. 18(Suppl. 6), vi81-vi85. doi: 10.1093/annonc/mdm232

Sleeman, K. E., Kendrick, H., Robertson, D., Isacke, C. M., Ashworth, A., and Smalley, M. J. (2007). Dissociation of estrogen receptor expression and in vivo stem cell activity in the mammary gland. J. Cell Biol. 176, 19-26. doi: 10.1083/ jcb. 200604065

Song, R. X.-D., McPherson, R. A., Adam, L., Bao, Y., Shupnik, M., Kumar, R., et al. (2002). Linkage of rapid estrogen action to MAPK activation by ERalphaShc association and Shc pathway activation. Mol. Endocrinol. 16, 116-127. doi: 10.1210/mend.16.1.0748

Stanisavljevic, J., Loubat-Casanovas, J., Herrera, M., Luque, T., Peña, R., Lluch, A., et al. (2015). Snaill-expressing fibroblasts in the tumor microenvironment display mechanical properties that support metastasis. Cancer Res. 75, 284-295. doi: 10.1158/0008-5472.CAN-14-1903

Stenoien, D. L., Patel, K., Mancini, M. G., Dutertre, M., Smith, C. L., O’Malley, B. W., et al. (2001). FRAP reveals that mobility of oestrogen receptor-alpha is ligand- and proteasome-dependent. Nat. Cell Biol. 3, 15-23. doi: 10.1038/ 35050515

Stossi, F., Madak-Erdoðan, Z., and Katzenellenbogen, B. S. (2012). Macrophageelicited loss of estrogen receptor- $\alpha$ in breast cancer cells via involvement of MAPK and c-Jun at the ESR1 genomic locus. Oncogene 31, 1825-1834. doi: 10.1038/onc. 2011.370
Strong, A. L., Ohlstein, J. F., Biagas, B. A., Rhodes, L. V., Pei, D. T., Tucker, H. A., et al. (2015). Leptin produced by obese adipose stromal/stem cells enhances proliferation and metastasis of estrogen receptor positive breast cancers. Breast Cancer Res. 17:112. doi: 10.1186/s13058-015-0622-z

Strong, A. L., Strong, T. A., Rhodes, L. V., Semon, J. A., Zhang, X., Shi, Z., et al. (2013). Obesity associated alterations in the biology of adipose stem cells mediate enhanced tumorigenesis by estrogen dependent pathways. Breast Cancer Res. 15:R102. doi: 10.1186/bcr3569

Talia, M., De Francesco, E. M., Rigiracciolo, D. C., Muoio, M. G., Muglia, L., Belfiore, A., et al. (2020). The G protein-coupled estrogen receptor (GPER) expression correlates with pro-metastatic pathways in er-negative breast cancer: a bioinformatics analysis. Cells 9:622. doi: 10.3390/cells9030622

Truong, T. H., Dwyer, A. R., Diep, C. H., Hu, H., Hagen, K. M., and Lange, C. A. (2019). Phosphorylated progesterone receptor isoforms mediate opposing stem cell and proliferative breast cancer cell fates. Endocrinology 160, 430-446. doi: 10.1210/en.2018-00990

Umayahara, Y., Kawamori, R., Watada, H., Imano, E., Iwama, N., Morishima, T., et al. (1994). Estrogen regulation of the insulin-like growth factor I gene transcription involves an AP-1 enhancer. J. Biol. Chem. 269, 16433-16442.

Vaniotis, G., Moffett, S., Sulea, T., Wang, N., Elahi, S. M., Lessard, E., et al. (2018). Enhanced anti-metastatic bioactivity of an IGF-TRAP re-engineered to improve physicochemical properties. Sci. Rep. 8:17361. doi: 10.1038/s41598018-35407-2

Varol, C. (2019). "Tumorigenic interplay between macrophages and collagenous matrix in the tumor microenvironment," in Collagen. Methods in Molecular Biology, Vol. 1944, eds I. Sagi and N. Afratis (New York, NY: Humana Press), 203-220. doi: 10.1007/978-1-4939-9095-5_15

Vella, V., Malaguarnera, R., Nicolosi, M. L., Morrione, A., and Belfiore, A. (2019a). Insulin/IGF signaling and discoidin domain receptors: an emerging functional connection. Biochim. Biophys. Acta BBA Mol. Cell Res. 1866:118522. doi: 10. 1016/j.bbamcr.2019.118522

Vella, V., Nicolosi, M. L., Giuliano, M., Morrione, A., Malaguarnera, R., and Belfiore, A. (2019b). Insulin receptor Isoform A modulates metabolic reprogramming of breast cancer cells in response to IGF2 and insulin stimulation. Cells 8:1017. doi: 10.3390/cells8091017

Vella, V., Malaguarnera, R., Nicolosi, M. L., Palladino, C., Spoleti, C., Massimino, M., et al. (2017). Discoidin domain receptor 1 modulates insulin receptor signaling and biological responses in breast cancer cells. Oncotarget 8, 4324843270. doi: 10.18632 /oncotarget. 18020

Vella, V., Pandini, G., Sciacca, L., Mineo, R., Vigneri, R., Pezzino, V., et al. (2002). A novel autocrine loop involving IGF-II and the insulin receptor Isoform-A stimulates growth of thyroid cancer. J. Clin. Endocrinol. Metab. 87, 245-254. doi: 10.1210/jcem.87.1.8142

Vicent, G. P., Ballaré, C., Nacht, A. S., Clausell, J., Subtil-Rodríguez, A., Quiles, I., et al. (2006). Induction of progesterone target genes requires activation of Erk and Msk kinases and phosphorylation of histone H3. Mol. Cell. 24, 367-381. doi: 10.1016/j.molcel.2006.10.011

Vigneri, P. G., Tirrò, E., Pennisi, M. S., Massimino, M., Stella, S., Romano, C., et al. (2015). The Insulin/IGF system in colorectal cancer development and resistance to therapy. Front. Oncol. 5:230. doi: 10.3389/fonc.2015.00230

Vivacqua, A., Muoio, M. G., Miglietta, A. M., and Maggiolini, M. (2019). Differential MicroRNA landscape triggered by estrogens in cancer associated fibroblasts (CAFs) of primary and metastatic breast tumors. Cancers 11:412. doi: $10.3390 /$ cancers 11030412

Walsh, L. A., and Damjanovski, S. (2011). IGF-1 increases invasive potential of MCF 7 breast cancer cells and induces activation of latent TGF- $\beta 1$ resulting in epithelial to mesenchymal transition. Cell Commun. Signal. 9:10. doi: 10.1186/ 1478-811X-9-10

Wang, L., Cossette, S. M., Rarick, K. R., Gershan, J., Dwinell, M. B., Harder, D. R., et al. (2013). Astrocytes directly influence tumor cell invasion and metastasis in vivo. PLoS One 8:e80933. doi: 10.1371/journal.pone.0080933

Waning, D. L., and Guise, T. A. (2014). Molecular mechanisms of bone metastasis and associated muscle weakness. Clin. Cancer Res. 20, 3071-3077. doi: 10.1158/ 1078-0432.CCR-13-1590

Webb, P., Lopez, G. N., Uht, R. M., and Kushner, P. J. (1995). Tamoxifen activation of the estrogen receptor/AP-1 pathway: potential origin for the cell-specific estrogen-like effects of antiestrogens. Mol. Endocrinol. 9, 443-456. doi: 10.1210/ me.9.4.443 
Wei, S., and Siegal, G. P. (2017). Metastatic organotropism: an intrinsic property of breast cancer molecular subtypes. Adv. Anat. Pathol. 24, 78-81. doi: 10.1097/ PAP.0000000000000140

Weilbaecher, K. N., Guise, T. A., and McCauley, L. K. (2011). Cancer to bone: a fatal attraction. Nat. Rev. Cancer 11, 411-425. doi: 10.1038/nrc3055

Weißenborn, C., Ignatov, T., Ochel, H.-J., Costa, S. D., Zenclussen, A. C., Ignatova, Z., et al. (2014). GPER functions as a tumor suppressor in triple-negative breast cancer cells. J. Cancer Res. Clin. Oncol. 140, 713-723. doi: 10.1007/s00432-0141620-8

West, N. R., Murray, J. I., and Watson, P. H. (2014). Oncostatin-M promotes phenotypic changes associated with mesenchymal and stem cell-like differentiation in breast cancer. Oncogene 33, 1485-1494. doi: 10.1038/onc. 2013.105

West, N. R., and Watson, P. H. (2010). S100A7 (psoriasin) is induced by the proinflammatory cytokines oncostatin-M and interleukin- 6 in human breast cancer. Oncogene 29, 2083-2092. doi: 10.1038/onc.2009.488

Williams, C. B., Yeh, E. S., and Soloff, A. C. (2016). Tumor-associated macrophages: unwitting accomplices in breast cancer malignancy. NPJ Breast Cancer 2:15025. doi: 10.1038/npjbcancer.2015.25

Wissmann, C., and Detmar, M. (2006). Pathways targeting tumor lymphangiogenesis. Clin. Cancer Res. Off. J. Am. Assoc. Cancer Res. 12, 6865-6868. doi: 10.1158/1078-0432.CCR-06-1800

Wu, T.-C., Xu, K., Martinek, J., Young, R. R., Banchereau, R., George, J., et al. (2018). IL1 receptor antagonist controls transcriptional signature of inflammation in patients with metastatic breast cancer. Cancer Res. 78, 52435258. doi: 10.1158/0008-5472.CAN-18-0413

Wyckoff, M. H., Chambliss, K. L., Mineo, C., Yuhanna, I. S., Mendelsohn, M. E., Mumby, S. M., et al. (2001). Plasma membrane estrogen receptors are coupled to endothelial nitric-oxide synthase through Galpha(i). J. Biol. Chem. 276, 27071-27076. doi: 10.1074/jbc.M100312200

Xu, X., Ye, J., Huang, C., Yan, Y., and Li, J. (2019). M2 macrophage-derived IL6 mediates resistance of breast cancer cells to hedgehog inhibition. Toxicol. Appl. Pharmacol. 364, 77-82. doi: 10.1016/j.taap.2018.12.013

Yager, J. D., and Davidson, N. E. (2006). Estrogen carcinogenesis in breast cancer. N. Engl. J. Med. 354, 270-282. doi: 10.1056/NEJMra050776

Ye, Y., Liu, S., Wu, C., and Sun, Z. (2015). TGF $\beta$ modulates inflammatory cytokines and growth factors to create premetastatic microenvironment and stimulate lung metastasis. J. Mol. Histol. 46, 365-375. doi: 10.1007/s10735-015-9633-4

Yee, D. (2012). Insulin-like growth factor receptor inhibitors: baby or the bathwater? J. Natl. Cancer Inst. 104, 975-981. doi: 10.1093/jnci/djs258

Yee, D. (2018). 40 YEARS OF IGF1: anti-insulin-like growth factor therapy in breast cancer. J. Mol. Endocrinol. 61, T61-T68. doi: 10.1530/JME-17-0261

Yee, L. D., Mortimer, J. E., Natarajan, R., Dietze, E. C., and Seewaldt, V. L. (2020). Metabolic health, insulin, and breast cancer: why oncologists should care about insulin. Front. Endocrinol. 11:58. doi: 10.3389/fendo.2020.00058

Yin, X., Wolford, C. C., Chang, Y.-S., McConoughey, S. J., Ramsey, S. A., Aderem, A., et al. (2010). ATF3, an adaptive-response gene, enhances TGF $\{$ beta $\}$ signaling and cancer-initiating cell features in breast cancer cells. J. Cell Sci. 123(Pt 20), 3558-3565. doi: 10.1242/jcs.064915

Yu, P. F., Huang, Y., Xu, C. L., Lin, L. Y., Han, Y. Y., Sun, W. H., et al. (2017). Downregulation of CXCL12 in mesenchymal stromal cells by TGF $\beta$ promotes breast cancer metastasis. Oncogene 36, 840-849. doi: 10.1038/onc.2016.252

Yuan, J., Liu, M., Yang, L., Tu, G., Zhu, Q., Chen, M., et al. (2015). Acquisition of epithelial-mesenchymal transition phenotype in the tamoxifen-resistant breast cancer cell: a new role for $\mathrm{G}$ protein-coupled estrogen receptor in mediating tamoxifen resistance through cancer-associated fibroblast-derived fibronectin and $\beta 1$-integrin signaling pathway in tumor cells. Breast Cancer Res. 17:69. doi: 10.1186/s13058-015-0579-y

Zelenko, Z., Gallagher, E. J., Antoniou, I. M., Sachdev, D., Nayak, A., Yee, D., et al. (2016). EMT reversal in human cancer cells after IR knockdown in hyperinsulinemic mice. Endocr. Relat. Cancer 23, 747-758. doi: 10.1530/ERC16-0142

Zervantonakis, I. K., Hughes-Alford, S. K., Charest, J. L., Condeelis, J. S., Gertler, F. B., and Kamm, R. D. (2012). Three-dimensional microfluidic model for tumor cell intravasation and endothelial barrier function. Proc. Natl. Acad. Sci. U.S.A. 109, 13515-13520. doi: 10.1073/pnas.1210182109

Zhang, H., Wong, C. C. L., Wei, H., Gilkes, D. M., Korangath, P., Chaturvedi, P., et al. (2012). HIF-1-dependent expression of angiopoietin-like 4 and L1CAM mediates vascular metastasis of hypoxic breast cancer cells to the lungs. Oncogene 31, 1757-1770. doi: 10.1038/onc.2011.365

Zhang, X. H.-F., Jin, X., Malladi, S., Zou, Y., Wen, Y. H., Brogi, E., et al. (2013). Selection of bone metastasis seeds by mesenchymal signals in the primary tumor stroma. Cell 154, 1060-1073. doi: 10.1016/j.cell.2013.07.036

Zhao, X.-B., and Ren, G.-S. (2016). Diabetes mellitus and prognosis in women with breast cancer: a systematic review and meta-analysis. Medicine 95:e5602. doi: 10.1097/MD.0000000000005602

Zhi, X., Zhang, Y., Huang, J., and Xu, H. (2017). Seven-membered lactam derivatives of podophyllotoxins as new pesticidal agents. Sci. Rep. 7:3917. doi: 10.1038/s41598-017-04136-3

Zhou, X., Wang, S., Wang, Z., Feng, X., Liu, P., Lv, X.-B., et al. (2015). Estrogen regulates Hippo signaling via GPER in breast cancer. J. Clin. Invest. 125, 2123-2135. doi: 10.1172/JCI79573

Conflict of Interest: The authors declare that the research was conducted in the absence of any commercial or financial relationships that could be construed as a potential conflict of interest.

Copyright $\odot 2020$ Vella, De Francesco, Lappano, Muoio, Manzella, Maggiolini and Belfiore. This is an open-access article distributed under the terms of the Creative Commons Attribution License (CC BY). The use, distribution or reproduction in other forums is permitted, provided the original author(s) and the copyright owner(s) are credited and that the original publication in this journal is cited, in accordance with accepted academic practice. No use, distribution or reproduction is permitted which does not comply with these terms. 